\title{
Too-big-to-fail Reforms and Systemic Risk
}

No.21-E-1

February 2021

\author{
Kakuho Furukawa* \\ kakuho.furukawa@boj.or.jp \\ Hibiki Ichiue ${ }^{\star \star}$ \\ hibiki.ichiue@boj.or.jp \\ Yugo Kimura $^{* \star \star}$ \\ yuugo.kimura@boj.or.jp \\ Noriyuki Shiraki ${ }^{*}$ \\ noriyuki.shiraki@boj.or.jp
}

\section{Bank of Japan}

2-1-1 Nihonbashi-Hongokucho, Chuo-ku, Tokyo 103-0021, Japan

*Financial System and Bank Examination Department

${ }^{* *}$ Financial System and Bank Examination Department (currently at the Naha Branch)

${ }^{* \star *}$ Financial System and Bank Examination Department (currently at the Personnel and Corporate Affairs Department)

Papers in the Bank of Japan Working Paper Series are circulated in order to stimulate discussion and comments. Views expressed are those of authors and do not necessarily reflect those of the Bank.

If you have any comment or question on the working paper series, please contact each author.

When making a copy or reproduction of the content for commercial purposes, please contact the Public Relations Department (post.prd8@boj.or.jp) at the Bank in advance to request permission. When making a copy or reproduction, the source, Bank of Japan Working Paper Series, should explicitly be credited. 


\title{
Too-big-to-fail Reforms and Systemic Risk*
}

\author{
Kakuho Furukawa $^{\dagger}$, Hibiki Ichiue ${ }^{\ddagger}$, Yugo Kimura ${ }^{\S}$, and Noriyuki Shiraki ${ }^{\Uparrow}$
}

\begin{abstract}
We examine the effects of too-big-to-fail reforms using $\triangle$ CoVaR and SRISK. Developments in these market-based systemic risk measures suggest that the reforms have led to a larger decline in the systemic risk contribution of global systemically important banks (G-SIBs) than of other banks. The systemic risk measures also suggest that the larger the systemic risk associated with a G-SIB, the more the reforms have led to a decline in its systemic risk. These findings are consistent with the objectives of the reforms and are validated by statistical analyses, including quantile panel regressions. We also highlight the importance of using data for a subset of financial institutions to adjust for the increase in data coverage when using popular estimates of SRISK. Furthermore, SRISK may overestimate systemic risk in recent years by ignoring the role of total loss absorbing capacity (TLAC)-eligible bonds.
\end{abstract}

Keywords: Too Big to Fail, Systemic Risk, Financial Regulations, CoVaR, SRISK

JEL Classification: G21, G23, G28

\footnotetext{
* The authors thank staff members of the Bank of Japan and members of the Financial Stability Board's evaluation working group on the effects of too-big-to-fail reforms, in particular Claudia Buch, Simon Firestone, and Nellie Liang, for their valuable comments. We are also grateful to Naohisa Hirakata and his coauthors for sharing the code to compute $\Delta \mathrm{CoVaR}$. All remaining errors are our own. The views expressed in this paper are those of the authors and do not necessarily reflect the official views of the Bank of Japan.

$\uparrow$ Financial System and Bank Examination Department, Bank of Japan (E-mail: kakuho.furukawa@boj.or.jp).

$¥$ Financial System and Bank Examination Department (currently at the Naha Branch), Bank of Japan (E-mail: hibiki.ichiue@boj.or.jp).

$\$$ Financial System and Bank Examination Department (currently at the Personnel and Corporate Affairs Department), Bank of Japan (E-mail: yuugo.kimura@boj.or.jp).

ศ Financial System and Bank Examination Department, Bank of Japan (E-mail: noriyuki.shiraki@boj.or.jp).
} 
"If the crisis has a single lesson, it is that the too-big-to-fail problem must be solved."

(Bernanke, 2010).

\section{Introduction}

As highlighted in the quote by the former Federal Reserve Chairman above, the financial crisis around 2008 revealed the extent to which a number of large financial institutions imposed severe negative externalities on the economy. The response to the crisis was a painful illustration of the "too-big-to-fail" (TBTF) problem: the system-wide impact of allowing such large institutions to fail meant that rather than letting the market take its course, a substantial amount of public funds had to be injected to maintain financial stability.

In addition to the costs borne by the taxpayer in a bailout, TBTF is also problematic because it induces financial institutions to take on more risk than is socially optimal. The reason is that expectation of a bailout leads such financial institutions to believe they will not bear the full costs associated with their actions, a problem known as moral hazard. Market discipline, which keeps financial institutions in check, may also be insufficient, since creditors become more willing to provide funding at lower rates, knowing that potential losses will be borne by the taxpayer.

At the G20 summit in Pittsburgh in 2009, leaders called on the Financial Stability Board (FSB), a newly founded international body created to promote international financial stability, to develop policy proposals to address the systemic and moral hazard risks associated with systemically important financial institutions. The FSB's policy framework for the TBTF reforms, endorsed by the G20 in 2010, proposed, among other things, that global systemically important financial institutions (G-SIFIs) should be required to have higher loss absorbency, that their resolvability should be assessed by financial authorities, and that they should prepare recovery and resolution plans.

International bodies have made progress in setting international standards in line with the FSB's proposal, in particular for banks. With regard to higher loss absorbency capacity, the Basel Committee on Bank Supervision (BCBS) in October 2011 published a framework to identify global systemically important banks (G-SIBs) and impose an 
additional capital surcharge (in the form of Common Equity Tier 1 capital) based on their systemic importance. The BCBS then published the first list of G-SIBs in the following month. The framework calculates banks' systemic importance score using five risk indicators linked to their size, interconnectedness, complexity, cross-border activity, and the substitutability of the services they provide. Banks above a certain threshold are identified as G-SIBs and become subject to a capital surcharge based on their score (see BCBS 2013). Since a higher score leads to a higher surcharge, the framework is expected to disincentivize banks from increasing their systemic importance. In addition, the capital surcharges are expected to strengthen G-SIBs' capital position and thereby decrease their probability of default.

Another key measure intended to increase loss absorbency is the requirement for G-SIBs to maintain a certain minimum total loss absorbing capacity (TLAC in the form of Basel regulatory capital and TLAC-eligible debt instruments). Whilst the capital surcharge mentioned above is intended to allow G-SIBs to absorb losses on a going-concern basis, the TLAC requirement ensures that they have sufficient loss absorbing capacity on a gone-concern basis so that, following resolution, the bank's critical functions can be continued without taxpayers' funds or financial stability being put at risk (see FSB 2015). Thus, the TLAC requirement should reduce the systemic risk associated with G-SIBs by reducing the impact of their failure. In addition, by making the resolution framework credible, the TLAC standard is expected to reduce expectations of a bailout, which in turn should affect banks' behavior in a way that leads to an internalization of their risk.

Detailed proposals related to requirements to ensure resolvability were set out in the initial publication of the Key Attributes of Effective Resolution Regimes for Financial Institutions (the "Key Attributes" or KA, see FSB 2011) in November 2011. The KA laid out core elements that authorities should incorporate in their resolution regime such as conducting resolvability assessments and putting in place an ongoing process for recovery and resolution planning for G-SIBs. Similar to the TLAC requirements, the implementation of the elements set out in the KA is expected to enhance the credibility of resolution and thereby reduce systemic and moral hazard risks associated with G-SIBs.

Against this background, the aim of this paper is to examine whether the TBTF reforms have led to the intended decrease in systemic risk. Specifically, we analyze two widely used market-based systemic risk measures: $\triangle \mathrm{CoVaR}$ (Adrian and Brunnermeier 2016) and SRISK (Acharya, Engle, and Richardson 2012, Brownlees and Engle 2017). Using these two measures in conjunction is appealing because of the complementary perspectives they offer. $\Delta \mathrm{CoVaR}$ regards financial institutions as a source of risk and 
measures the stress in the financial system conditional on the distress of an individual financial institution. On the other hand, SRISK treats financial institutions as recipients of risk and is defined as the expected capital shortfall of an institution conditional on a systemic event. Another difference between $\triangle \mathrm{CoVaR}$ and SRISK is that the former is computed only from market data, whilst SRISK additionally incorporates information on balance sheets (debt and market capitalization). Although we are mainly interested in banks, we compute these systemic risk measures for other types of financial institutions for comparison. We compute these measures for each institution to examine the systemic risk contribution of an institution and also aggregate these measures for different financial institution subcategories such as G-SIBs and other banks.

Developments in the two market-based systemic risk measures suggest that the TBTF reforms have led to a decline in systemic risk. Specifically, the $\Delta \mathrm{CoVaR}$ of a larger share of G-SIBs than other banks decreased from before the financial crisis to after the major TBTF reforms such as the initial publication of the G-SIB framework in 2011. This finding suggests that the TBTF reforms have had the desired effect since G-SIBs were the main target of the TBTF reforms. Additional analysis of $\triangle \mathrm{CoVaR}$ further indicates that, among G-SIBs, the greater their systemic risk contribution was in the period before the crisis, the more their contribution has fallen, which is consistent with the objectives of the TBTF reforms.

SRISK, which is estimated by the Volatility Laboratory of the NYU Stern Volatility and Risk Institute (V-Lab), ${ }^{2}$ provides similar results as $\Delta$ CoVaR. In the analysis of SRISK, we highlight the importance of focusing on a subset of financial institutions that have existed since before the financial crisis, since the rapid growth in V-Lab's data coverage has the effect of pushing up SRISK aggregated across financial institutions and masks the effect of the reforms. We also point out that SRISK may overestimate the systemic risk contribution of individual financial institutions as well as aggregate systemic risk in recent years since it is computed based on the assumption that only equity can be used to absorb losses and the government would have to cover the remaining losses. In practice, however, large banks have enhanced their capacity to absorb losses by issuing TLACeligible bonds since 2013. It therefore seems reasonable to subtract a certain proportion of TLAC-eligible debt from the SRISK of an individual institution, where the proportion reflects the extent to which TLAC-eligible bond holders can absorb losses. Taking TLAC-eligible debt into account, we find stronger evidence that the TBTF reforms had

${ }^{2}$ See https://vlab.stern.nyu.edu/welcom/srisk. 
the desired effects.

We conduct a number of regression analyses and find statistically significant results that are consistent with the preliminary examination of $\Delta \mathrm{CoVaR}$ and SRISK just described. Specifically, we employ difference-in-difference (DID) estimation to take into account that while many factors - such as low interest rates and other regulatory changes (e.g., Basel III) - have affected the risks of all banks, the TBTF reforms may have had a stronger effect on banks that have been subject to the reforms than banks that have not. Concretely, we first run linear panel regressions and find that the TBTF reforms have led to a decline in the systemic risk contribution of G-SIBs. We then employ the quantile panel regression approach proposed by Powell (2016) and find that the larger the systemic risk associated with a G-SIB, the more the reforms have led to a decline in its systemic risk.

Our study contributes to recent work by policy makers on evaluating the effectiveness of the TBTF reforms. With a large part of major reforms having been implemented and several years' worth of data at hand, this area is receiving increased attention among financial regulators. In particular, the FSB has been conducting a comprehensive evaluation of the effects of the TBTF reforms since early 2019, to which the analyses in this paper have also contributed (see FSB 2020). The BCBS has also released related papers in recent years. For example, BCBS (2019) shows that systemic importance indicators calculated under the G-SIB framework have developed differently for G-SIBs and other banks. Whilst G-SIBs have reduced their indicators by shrinking their balance sheets in ways consistent with the G-SIB framework's aims, other banks have increased their indicators during the same period.

This paper also adds to the academic literature. As the survey in FSB (2020) shows, there is a vast literature tackling TBTF-related issues, in particular whether the funding cost advantages of systemically important banks have diminished. In addition, there are also a large number of studies using market-based systemic risk measures for different purposes; for instance, Brunnermeier, Rother, and Schnabel (2020) analyze the relationship between asset price bubbles and systemic risk. However, to the best of our knowledge, this paper is the first to link these strands and identify the effects of the TBTF reforms using market-based systemic risk measures. The study most relevant to our analysis is that by Sarin and Summers (2016), who compare various market measures, including a systemic risk indicator similar to SRISK, for the period before the global financial crisis (which they generally define as 2002-2007) and the period after the crisis (which they generally define as 2010-2015) and conclude that large banks became more 
vulnerable to adverse shocks. In contrast, we focus particularly on the effects of the major TBTF reforms in 2011, employ statistical methods, including quantile panel regressions, take TLAC-eligible debt into account, and find evidence suggesting that the reforms did have the desired effect of reducing systemic risk.

The remainder of this paper is organized as follows. Sections 2 and 3 describe the construction of $\triangle \mathrm{CoVaR}$ and SRISK respectively and use these measures to examine the evolution of systemic risk in the wake of the TBTF reforms. Next, Section 4 presents the results of our regression analyses. Finally, Section 5 concludes this paper.

\section{2. $\Delta$ CoVaR}

\subsection{Method and Data}

$\triangle \mathrm{CoVaR}$ is a systemic risk measure proposed by Adrian and Brunnermeier (2016). Formally, $\operatorname{CoVaR} R_{i t}^{m \mid \mathbb{C}\left(r_{i t}\right)}(\alpha)$ is defined as the value at risk (VaR) of the financial system conditional on event $\mathbb{C}\left(r_{i t}\right)$ affecting institution $i$ :

$$
\operatorname{Pr}\left(-r_{m t} \leq \operatorname{CoVaR} R_{i t}^{m \mid \mathbb{C}\left(r_{i t}\right)}(\alpha) \mid \mathbb{C}\left(r_{i t}\right)\right)=\alpha \%
$$

where $r_{m t}$ is the market return (i.e., the stock return of the financial system) and $r_{i t}$ is the stock return of institution $i$. Given this, $\triangle \mathrm{CoVaR}$ is defined as

$$
\Delta \operatorname{CoVaR} R_{i t}(\alpha)=\operatorname{CoVaR}_{i t}^{m \mid-r_{i t}=\operatorname{VaR}_{i t}(\alpha)}-\operatorname{CoVaR}_{i t}^{m \mid-r_{i t}=\operatorname{VaR} i t(50)}
$$

where $\operatorname{VaR}_{i t}(\alpha)$ is the VaR of institution $i$ given by

$$
\operatorname{Pr}\left(-r_{i t} \leq \operatorname{VaR}_{i t}(\alpha)\right)=\alpha \% \text {. }
$$

As pointed out by Adrian and Brunnermeier (2016), $\Delta$ CoVaR satisfies the "clone property." That is, after splitting one large systemic institution into smaller clones, the $\Delta \mathrm{CoVaR}$ of the clones is exactly the same as that of the large institution. To take the size of an institution into account, Adrian and Brunnermeier (2016) use $\Delta^{\$} \mathrm{CoVaR}$, which is calculated as $\triangle \mathrm{CoVaR}$ times the market equity of an institution. Based on a similar line of reasoning, we calculate the aggregate $\triangle \mathrm{CoVaR}$ of a particular set of financial institutions by taking the average of the $\Delta \mathrm{CoVaR}$ of all the individual institutions in that set using their market equity as weights. 
Like Adrian and Brunnermeier (2016), we compute $\Delta \mathrm{CoVaR}$ via quantile regressions. ${ }^{3}$ We set $\alpha$ at 95 and use market capitalization data for all actively traded financial institutions with a market capitalization of more than $€ 10$ billion as of FY 2018 obtained from Bloomberg. Our sample consists of 832 financial institutions across 67 jurisdictions. The data are of daily frequency and span the years 2000 to 2019. We categorize financial institutions by sector (bank, insurance, asset management, and other) following the Bloomberg Industry Classification Standard and by jurisdiction based on where their ultimate parent company is headquartered. Our panel data are unbalanced due to missing data for days on which shares are not traded and due to the entry of new institutions into the sample as a result of initial public offerings. ${ }^{4}$ Missing data are substituted with the last available observation up to six days before.

Returns are calculated on a weekly basis, following Adrian and Brunnermeier (2016). Use of weekly returns alleviates the problem that arises when using data from different time zones, as in our analysis. For instance, if we consider two banks whose shares are traded in New York and Tokyo, respectively, since the time zones differ, the market returns of the banks on a particular day are in fact calculated at different points in time, which would reflect a different set of events. In contrast, weekly returns essentially reflect the same set of events. The return data are then winsorized at the $99.99 \%$ and $0.01 \%$ levels to deal with outliers that have arisen presumably due to poor data quality, public offerings, repurchases of shares, and other factors.

We divide observations for the financial institutions in our sample into time periods for which we want to calculate $\triangle \mathrm{CoVaR}$. While in the baseline analysis, we calculate $\Delta \mathrm{CoVaR}$ on a calendar year basis, we also check the robustness of our results using other time periods. Due to the unbalanced nature of our data, we only include institutions for which we have data for more than 100 days during each estimation window. To calculate the market return of the overall global financial system market portfolio, we use the weighted average of returns of individual financial institutions based on the market value, following Brunnermeier, Rother, and Schnabel (2020).

\subsection{Results}

Figure 1 shows that global $\Delta \mathrm{CoVaR}$, which is the weighted average of the $\Delta \mathrm{CoVaR}$ of all institutions in our sample, surged in 2008 and has declined since then. Looking at the

\footnotetext{
${ }^{3}$ We employ Hirakata, Kido, and Thum's (2020) code to compute $\Delta$ CoVaR.

${ }^{4}$ For instance, China Construction Bank, a G-SIB, entered our sample only in 2015, when it made an initial public offering on the Stock Exchange of Hong Kong.
} 
observation period overall, although $\triangle \mathrm{CoVaR}$ has fluctuated considerably and spiked during the global financial crisis, it does not display a clear trend. These findings are more or less in line with the literature. For example, Adrian and Brunnermeier (2016) and Benoit et al. (2017) show that $\triangle \mathrm{CoVaR}$ was high during the crisis but low both before and after the crisis. Next, Figure 2 shows the distribution of $\Delta \mathrm{CoVaR}$ for individual financial institutions. The figure indicates that the distribution for our latest data point, 2019, lies to the left of that for the peak of the crisis in 2008. Further, the broad shift in the distribution shows that the decline in global $\Delta \mathrm{CoVaR}$ seen in Figure 1 was driven not by a certain group of institutions but by a broad-based decline in $\Delta \mathrm{CoVaR}$.

To examine whether trends differed across regions, we construct separate $\Delta \mathrm{CoVaR}$ measures for advanced economies (AE) and emerging markets (EM). Figure 3(a) shows that $\triangle \mathrm{CoVaR}$ has been lower for EM throughout the observation period. A further breakdown of financial institutions into sectors is shown in Figure 3(b). Given that $\Delta \mathrm{CoVaR}$ shows significant yearly fluctuations, the figure compares the average $\Delta \mathrm{CoVaR}$ for the period before the global financial crisis and the period following the TBTF reforms, where the former, following Sarin and Summers (2016), is defined as 2002-2007, while the latter is defined as 2012-2019, since the G-SIB framework, the G-SIB list, and the KA were all initially published in the fourth quarter of 2011. Consistent with our previous finding, all sectors exhibit a higher $\triangle \mathrm{CoVaR}$ in $\mathrm{AE}$ than in EM. However, whilst in AE all sectors saw either a reduction or at most a marginal increase in $\triangle \mathrm{CoVaR}$, in EM a clear increase can be seen for all sectors. This likely reflects the growing presence of EM financial institutions in the global financial system.

Finally, we examine $\Delta \mathrm{CoVaR}$ for G-SIBs and other banks. ${ }^{5}$ As one would expect, $\triangle \mathrm{CoVaR}$ has been almost consistently higher for G-SIBs than for other banks (Figure 4(a)). However, examination of $\triangle \mathrm{CoVaR}$ for individual institutions also suggests that the difference between G-SIBs and other banks has narrowed since the TBTF reforms. Plotting individual institutions' average $\triangle \mathrm{CoVaR}$ for the period after the reforms against that for the period before the financial crisis, we find that approximately $50 \%$ of G-SIBs saw a decline in their $\Delta \mathrm{CoVaR}$ compared to approximately $20 \%$ of other banks (Figure $4(b))$. The fact that the $\triangle \mathrm{CoVaR}$ of a larger share of G-SIBs than other banks has decreased suggests that the TBTF reforms indeed contributed to a reduction in systemic risk. Another indication that the reforms appear to have had the intended effect is that in Figure 4(b) $\triangle \mathrm{CoVaR}$ of G-SIBs associated with greater systemic risk before the crisis has

\footnotetext{
5 Throughout this paper, G-SIBs are defined as all banks that at some point have been among the financial institutions classified as G-SIBs by the FSB since the publication of the initial list in 2011.
} 
tended to decrease to a larger extent following the reforms, as indicated by the fact that the further solid black circles are to the right, the more they tend to fall below the 45 degree line.

\section{SRISK}

\subsection{Method and Data}

SRISK is a systemic risk measure introduced by Acharya, Engle, and Richardson (2012) and Brownlees and Engle (2017). The SRISK of a financial institution is defined as the expected capital shortfall of the institution conditional on a systemic event and can be interpreted as the expected amount of capital that the government would have to provide to bail out that financial institution. Formally, SRISK $K_{i t}$ of financial institution $i$ at time $t$ is expressed as

$$
S R I S K_{i t}=k \cdot D_{i t}-(1-k) \cdot W_{i t} \cdot\left(1-L R M E S_{i t}\right)
$$

where $k$ is the prudential capital ratio (typically assumed to be $8 \%$ by V-Lab), $D_{i t}$ is the book value of debt, and $W_{i t}$ is the equity or market capitalization of financial institution i. LRMES $S_{i t}$ is the Long-Run Marginal Expected Shortfall or the expected percent equity loss of institution $i$ conditional on a systemic event. Note that, in contrast with $\triangle \mathrm{CoVaR}, \mathrm{SRISK}$ is size dependent: a one-percent increase in debt and equity results in a one-percent increase in SRISK when the LRMES is fixed. Furthermore, since SRISK is positively associated with debt and negatively associated with equity, SRISK by definition likely is positively correlated with the debt-to-market capitalization ratio.

In this section, we examine aggregate SRISK for a particular set of jurisdictions and financial institutions. Specifically, we calculate the aggregate SRISK of a particular category of financial institutions $C$ as

$$
S R I S K_{t}=\sum_{i \in C} \max \left(S R I S K_{i t}, 0\right) .
$$

Note that in the computation of aggregate SRISK, the negative part of individual institutions' SRISK or expected capital shortfall - that is the positive part of their expected capital surplus - conditional on a systemic event is ignored. The reason is that it is unlikely that financial institutions will mobilize surplus capital through mergers or loans to support failing financial institutions during a crisis.

Estimates of SRISK for individual institutions have been provided by V-Lab. Specifically, among the various SRISK measures provided by V-Lab, we focus on the SRISK 
computed when the systemic event is defined as a significant decline in a global market index (the MSCI ACWI index) by more than 40\% over a six-month period, as in Engle and Ruan (2019). The dataset includes an indicator of whether an institution is "alive" or "dead." Where there are missing data points, we filled in the data using the most recently available figures unless the institution in question is regarded as "dead." The classification of financial institutions into different sectors is based on the Bloomberg Industry Classification Standard.

Possibly in part due to public offerings, a substantial number of financial institutions especially from EM - enter the sample in the period after the financial crisis. We therefore compute SRISK for two samples: a "full sample" of all financial institutions and a "balanced sample" consisting of financial institutions that have been in the sample since 2007, the last year of the period before the crisis. Whilst the full sample provides insights on the overall level of systemic risk, especially for recent years, the balanced sample allows us to compare systemic risk in the period before the crisis and the period after the reforms, thus making it possible to better examine the effect of the TBTF reforms, since it is based on the same set of financial institutions. For comparison, the subsequent analyses will refer to both the full sample and the balanced sample.

\subsection{Results}

The full sample result in Figure 5(a) shows that after a rapid increase in 2008, aggregate SRISK for all institutions in the sample was more or less flat or on a slightly upward trend. However, as discussed above, the increase in financial institutions covered may have pushed the trend up. ${ }^{6}$ In fact, when we use the balanced sample, aggregate SRISK has declined from the peak in 2009. Furthermore, given that SRISK depends on the size of financial institutions, it is useful to examine SRISK in relation to the size of the economy such as gross domestic product (GDP), as reported on the V-Lab website. If we measure SRISK as a ratio to global GDP, we again find that SRISK has followed a declining trend, this time both for the full and the balanced sample, although recent levels still remain higher than before the crisis (Figure 5(b)). In the remainder of this section, we mainly focus on SRISK as a ratio to global GDP based on the balanced sample, although we also show the full-sample SRISK in several figures for comparison.

Figure 6 looks at SRISK by region. Starting with panel (a) for the full sample, this shows

\footnotetext{
${ }^{6}$ For instance, SRISK for Chinese banks exhibits a significant increase over our observation period due in part to more Chinese banks becoming publicly traded.
} 
that while SRISK has been on a gradual decline in AE after the crisis, it has been increasing in EM. Again, the latter trend reflects the addition of financial institutions to the sample. Next, panel (b) shows SRISK by region based on the balanced sample and as a percentage of GDP. In this case, the decline in SRISK for AE is considerably more pronounced, while SRISK for EM remains essentially unchanged. To examine the trends in Figure 6(b) in more detail, Figure 7 shows SRISK by sector. The figure indicates that both in AE and EM banks have been the predominant contributor to SRISK. In particular, the upward trend in SRISK of banks in EM stands out. Whilst in AE the insurance sector and, to a lesser extent, other nonbank financial institutions to a certain degree have contributed to SRISK overall, this does not seem to be the case in EM. One reason why nonbank financial institutions in EM do not have a significant impact on SRISK could be that many of such financial institutions in EM are not listed.

Next, Figure 8 shows SRISK within the banking sector, distinguishing between G-SIBs and other banks. Starting with panel (a) for the full sample, this indicates that SRISK surged during the crisis for both G-SIBs and other banks. Moreover, while it subsequently remained unchanged at this elevated level for G-SIBs, it continued to increase for other banks. Looking at the balanced sample and as a percentage of GDP (panel (b)), SRISK for G-SIBs has been on a clear downward trend since the crisis, while for other banks the decline since the peak in 2009 is much less pronounced. These somewhat diverging trends suggest a shift in risk from G-SIBs to other banks. Nonetheless, the SRISK of G-SIBs is still higher than before the crisis. This result is consistent with Sarin and Summers's (2016) argument that banks became more vulnerable to adverse shocks, based on their finding that for most major banks the ratio of the market value of common equity to assets declined significantly from the pre-crisis period to the post-crisis period.

That said, it is possible that SRISK overestimates systemic risk since it is computed based on the assumption that only equity can be used to absorb losses and that the government would have to cover any remaining losses. In practice, however, large banks have enhanced their capacity to absorb losses by issuing TLAC-eligible bonds to satisfy the requirements of the TBTF reforms. It therefore seems reasonable to subtract TLACeligible debt from the SRISK of an individual institution. On the other hand, TLACeligible debt holders may not absorb losses. The reason is that, as concluded by FSB (2020), although significant progress has been made in enhancing the resolvability of banks, there are still gaps that need to be addressed. For instance, resolution authorities need to weigh up whether the benefit of avoiding bailout by forcing TLAC-eligible debt holders to absorb losses is outweighed by the potential costs of a negative contagion effect 
on the financial system possibly through cross-holdings of TLAC-eligible debt across banks. In part because information on the TLAC investor base at this stage is limited, as pointed out by FSB (2020), resolution authorities may hesitate to require TLAC-eligible debt holders to absorb losses. Given that it is still difficult to estimate the probability of bailout, to get a sense of the effect of TLAC-eligible debt on systemic risk, we subtract half and all of TLAC debt from the SRISK for an individual institution. We obtain daily data for TLAC-eligible bond issuance from Bloomberg and calculate the debt outstanding by cumulating issuances based on the assumption that no bonds were called or matured. This is a plausible assumption, since G-SIBs have been issuing TLAC-eligible bonds to satisfy the final minimum requirements, which apply from January 2022.

Figure 9(a) compares aggregate SRISK as a ratio to global GDP using the balanced sample when TLAC bonds are not taken into account, when half are taken into account, and when all are taken into account. The figure shows that even though SRISK currently remains above the level before the crisis, once half or all TLAC bonds are taken into account, SRISK is at around the same level as before the crisis. Next, Figure 9(b), which focuses on G-SIBs only, shows that their SRISK is actually lower than before the crisis even when only half of TLAC bonds are taken into account. In fact, as suggested by the relatively small improvement in SRISK when comparing the inclusion of half of TLAC bonds and all of TLAC bonds, the decline in systemic risk through the issuance of TLAC debt is subject to "diminishing returns," since aggregate SRISK does not count individual institutions' TLAC debt beyond their capital shortfall.

Finally, in Figure 10 we examine the SRISK distribution of G-SIBs in 2007, the last year of the pre-crisis period, and in 2019, the last year for which data are available. Figure 10(a) shows that the distribution of original SRISK without the adjustment for TLAC bonds has shifted the right, suggesting that the SRISK of G-SIBs today is higher than before the crisis. Another notable feature is that the distribution has converged onto a slightly positive value. This result is consistent with Figure 4(b), which suggests that the distribution of the $\triangle \mathrm{CoVaR}$ of G-SIBs has converged somewhat from the pre-crisis to the post-reform period (indicated by the fact that the vertical spread of the observations is smaller than the horizontal spread). Figure 10(b), which plots SRISK minus all TLAC debt, also shows that the distribution has converged onto a slightly positive value to some extent, although it has clearly shifted to the left, indicating that the systemic risk contribution of G-SIBs today is smaller than before the crisis once TLAC-eligible bonds are fully taken into account. 


\section{Regression Analysis}

The preliminary analyses in the preceding sections suggest that the TBTF reforms do appear to have had the desired effects. In this section, to examine whether these results can be validated in statistical analyses, we conduct a range of different panel regressions. Specifically, we use a DID approach, where we compare developments in the systemic risk measure of G-SIBs (the treatment group) relative to other banks (the control group), to take into account that while many factors such as Basel III have affected the risks of all banks, the TBTF reforms may have had a stronger effect on banks that have been subject to the reforms than on banks that have not. Our baseline regression uses time dummies to examine whether market-based systemic risk measures declined from the precrisis period to the post-reform period to a larger extent for G-SIBs than for other banks. We then check the robustness of our results by using, for instance, a proxy variable that represents the degree to which individual jurisdictions have implemented resolution reforms instead of time dummies. Finally, we run a panel quantile regression, which enables us to investigate the effect of the TBTF reforms on G-SIBs at different quantiles within the overall distribution.

\subsection{Baseline Specification with Time Dummies}

The baseline specification for our DID estimation is as follows:

$$
Y_{i j t}=\alpha_{i}+\alpha_{j t}+\sum_{k=1}^{4} \beta_{k} \cdot g_{i j} \cdot \tau_{k t}+\varepsilon_{i j t}
$$

The dependent variable $Y_{i j t}$ is the market-based systemic risk measure, $\Delta \mathrm{CoVaR}$ or SRISK, for bank $i$ in jurisdiction $j$ in year $t$. The observation period is from 2000 to 2019. $\alpha_{i}$ represents bank fixed effects and controls for heterogeneity across banks, while $\alpha_{j t}$ represents jurisdiction-time fixed effects and controls for jurisdiction-specific timevarying heterogeneity. $g_{i j}$ is a dummy variable that takes 1 for a G-SIB and 0 otherwise. $\tau_{1 t}, \tau_{2 t}, \tau_{3 t}$, and $\tau_{4 t}$ are dummy variables that take 1 during the period of the tech bubble and its burst (2000-2001), the period before the global financial crisis (20022007), the crisis period (2008-2009), and the post-crisis-but-pre-reform period (20102011), respectively, and 0 otherwise. The post-TBTF-reform period (2012-2019) acts as the reference period. The coefficient of interest is $\beta_{2}$, which is expected to be positive if the extent to which the systemic risk measure in the post-reform period is lower than in the pre-crisis period is larger for G-SIBs than for other banks. Standard errors are clustered at the bank level for all regressions in this paper. 
While annual data for the $\triangle \mathrm{CoVaR}$ of an individual financial institution are used as they are, a few steps are necessary to construct corresponding data for SRISK. First, to obtain annual data for SRISK, we average the daily SRISK data. We then normalize the annual SRISK data using the annual average of a financial institution's total assets (calculated as the sum of debt and market capitalization). For the analysis, we select only banks that are located in FSB jurisdictions ${ }^{7}$ and have total assets greater than $€ 10$ billion to ensure that the control group for the DID analysis is comparable to the G-SIBs in the treatment group.

Columns (1) to (4) in Table 1 report the estimated coefficients of the interaction term between the G-SIB dummy and the time dummy for $\Delta \mathrm{CoVaR}$, the original SRISK (i.e., without TLAC adjustment), SRISK minus half of TLAC-eligible debt, and SRISK minus all TLAC debt, respectively. The coefficient for the pre-crisis period is, as expected, positive and significant at least at the 5\% level for $\triangle$ CoVaR and SRISK minus all TLAC debt. The insignificant result for the original SRISK likely is due to the fact that the measure ignores TLAC debt.

For the baseline estimation in Table 1, the post-reform period was defined as the period 2012-2019, since the initial publication of the G-SIB framework, the G-SIB list, and the KA in the fourth quarter of 2011 is extremely important for the TBTF reforms. However, this definition may have some drawbacks. For instance, the European debt crisis in 2012 may have affected the market-based systemic risk measures, potentially masking the impact of the TBTF reforms. Furthermore, while the forward-looking nature of financial markets means that the market-based systemic risk measures may have responded immediately to the publication of the major elements of the TBTF reforms, it is also possible that the response of the risk measures may have been slow and to some extent occurred not when the TBTF measures were announced but when they started to be implemented.

To examine the implementation status of the TBTF reforms, it is useful to look at the Resolution Reform Index (RRI) constructed and published by the FSB. Although this index captures only resolution reforms - a subset of the TBTF reforms - it does provide an indication of the progress in the reform implementation. The RRI is calculated from various pieces of information about the adoption of resolution powers and recovery and resolution planning, the development of policies and guidance to operationalize resolution regimes, and bail-in powers and the existence of external loss-absorbing

7 The FSB jurisdictions consist of Argentina, Australia, Brazil, Canada, China, France, Germany, Hong Kong SAR, India, Indonesia, Italy, Japan, Korea, Mexico, the Netherlands, Russia, Saudi Arabia, Singapore, South Africa, Spain, Switzerland, Turkey, the United Kingdom, and the United States. 
capacity requirements for systemically important banks (see FSB 2020 for further details). The RRI score for a particular jurisdiction ranges from 0 to 1 , where 0 denotes no implementation and 1 full implementation. Figure 11 shows the medians of the RRI for G-SIB home jurisdictions and other jurisdictions. The figure suggests that while implementation was very limited in 2012, just after the major TBTF reforms, G-SIB host jurisdictions reached close to full implementation in 2019.

Thus, to address the possibility that the market-based systemic risk measures may have been slow to respond, we check the robustness of our results by defining the post-crisisbut-pre-reform period as 2010-2015 instead of 2010-2011. The results are presented in Table 2 and provide stronger support that the TBTF reforms reduced systemic risk. Specifically, the coefficient on SRISK minus half of TLAC debt for the pre-crisis period, which was insignificant in Table 1, is now significantly positive at the level of 5\%.

As a further robustness check, we run a separate regression using the RRI for a given jurisdiction instead of time dummies. While the RRI only captures developments in a subset of the TBTF reforms, its jurisdiction-specific nature allows us to exploit heterogeneity in the pace of implementation of the reforms. Unfortunately, the RRI starts only in 2010. However, while some jurisdictions already had implemented their own resolution reforms before 2011 that were consistent with the subsequent international reforms, such implementation was very limited. In fact, as shown in Figure 11, the median of the RRI was less than 0.1 in 2010 even for G-SIB home jurisdictions. It therefore appears to be possible to extrapolate the index backward in an accurate manner. Specifically, we run regressions using the following three alternative indexes: the original RRI; an extrapolated RRI that is assumed to be zero before 2010; and an extrapolated RRI that is assumed to take the same value as in 2010 . The observation period is from 2010 for the original RRI while it is from 2000 for the other two indexes.

We run the following panel regression:

$$
Y_{i j t}=\alpha_{i}+\alpha_{j t}+\beta \cdot g_{i j} \cdot R R I_{j t}+\varepsilon_{i j t},
$$

where $R R I_{j t}$ is the aforementioned RRI in jurisdiction $j$ in year $t$. Since the systemic risk measure is expected to decline as the RRI increases (i.e., more resolution reforms are implemented) to a larger extent for G-SIBs than for other banks, $\beta$ is expected to be negative.

Table 3 reports the estimated coefficients of the interaction term between the G-SIB dummy and the RRI. The first column shows that the coefficient is insignificant for 
$\Delta \mathrm{CoVaR}$ when using the original RRI, possibly because of the limited observation period; however, it is significantly negative when using either of the extrapolated RRIs, as expected. In contrast, the results for the original SRISK in the second column show that the coefficient is never significantly different from zero. On the other hand, the third and fourth columns show that the coefficient is negative for all three alternative RRIs when taking TLAC debt into account and is significantly different from zero in five cases out of six. Overall, the results suggest that the resolution reforms have reduced systemic risk, although some results are not statistically significant, possibly because the RRI is available only from 2010 or because we ignore the role of TLAC debt.

\subsection{Quantile regressions}

In the previous subsection we looked at the average treatment effect of the TBTF reforms. However, as discussed in Sections 2 and 3, the TBTF reforms may have had a greater effect on G-SIBs associated with greater systemic risk. To examine this point more rigorously, we employ the quantile panel regression approach proposed by Powell (2016). The regressions correspond to the baseline specification (6) and alternative specification (7). Specifically, for quantile $q=0.1,0.2, \ldots, 0.9$, we estimate the following quantile functions:

$$
\begin{gathered}
S_{Y_{i j t}}\left(q \mid g_{i j}, \tau_{1 t}, \tau_{2 t}, \tau_{3 t}, \tau_{4 t}\right)=\alpha(q) \cdot g_{i j}+\sum_{k=1}^{4}\left[\beta_{k}(q) \cdot g_{i j} \cdot \tau_{k t}+\gamma_{k}(q) \cdot \tau_{k t}\right] \\
S_{Y_{i j t}}\left(q \mid g_{i j}, R R I_{j t}\right)=\alpha(q) \cdot g_{i j}+\beta(q) \cdot g_{i j} \cdot R R I_{j t}+\gamma(q) \cdot R R I_{j t}
\end{gathered}
$$

The results of these quantile regressions can be interpreted in a similar way as those of the panel regressions used in the previous subsection. For example, in equation (8), $\beta_{2}(0.9)$ is expected to be positive if the extent to which the systemic risk measure in the post-reform period is lower than in the pre-crisis period is larger for G-SIBs than for other banks at the $90^{\text {th }}$ percentile (i.e., for banks associated with relatively greater systemic risk). We expect that $\beta_{2}(q)$ increases with $q$ if the TBTF reforms have had a greater effect on G-SIBs associated with greater systemic risk. Similarly, in equation $(9), \beta(q)$ is expected to decrease with $q$ if the implementation of the resolution reforms has had a greater effect on G-SIBs associated with greater systemic risk. We do not use the original RRI here because we find that the estimates do not converge in the iterative procedure, which is likely due to the short observation period for the variable. Instead, we use the extrapolated RRI that is assumed to be zero before 2010. Note that we obtain similar results when using the extrapolated RRI that is assumed to take the same value as in 2010 for earlier years. Below, we present the results in the form of figures and omit tables to 
conserve space. However, all detailed regression results are available from the authors upon request.

Figure 12 shows the estimation results for $\beta_{2}(q)$ in equation (8). Panels (a), (b), (c), and (d) plot the point estimates with the $90 \%$ confidence interval at various quantiles for $\triangle \mathrm{CoVaR}$, SRISK, SRISK minus half of TLAC debt, and SRISK minus all TLAC debt, respectively. All panels show the pattern that the coefficient $\beta_{2}(q)$ increases with quantile $q$, as expected. Figure 13 shows similar results for equation (9). As expected, the coefficient $\beta(q)$ tends to be lower for higher quantiles.

Figure 12 also shows that the coefficient is negative when $q$ is low, in particular for SRISK and SRISK minus half of TLAC debt. Similarly, Figure 13 shows that the coefficient is significantly positive when $q$ is low for SRISK and SRISK minus half of TLAC debt. Although these results suggest that the TBTF reforms have led to an increase in the SRISK of G-SIBs in the lower SRISK quantiles, especially when TLAC debt is not taken into account, this does not necessarily mean that these G-SIBs have had an upward impact on the aggregate SRISK. The reason is that, as shown in equation (5), negative values of the SRISK of an individual financial institution do not influence the aggregate SRISK. Therefore, if the SRISK of an individual financial institution has increased only in negative territory (moved closer to zero), this does not lead to an increase in the aggregate SRISK. Since SRISK has been negative for a majority of G-SIBs in the low quantiles, the impact of an increase in the SRISK of these G-SIBs on the aggregate SRISK likely has been limited.

To illustrate this, Figure 14 shows how using the positive part of the original or the TLACdebt-adjusted SRISK changes our results with time dummies presented in Figure $12 .{ }^{8}$ Overall, the coefficient $\beta_{2}(q)$ for the original and adjusted SRISK is higher in Figure 14 than in Figure 12, in particular for lower quantiles. This result suggests that although the SRISK of individual G-SIBs in lower quantiles has increased following the TBTF reforms, a large part of the increase is due to a decrease in their expected capital surplus rather than due to an increase in their expected capital shortfall conditional on a systemic event, so that the extent to which this has led to an increase in aggregate systemic risk is limited.

\section{Conclusion}

\footnotetext{
${ }^{8}$ We also tried using the positive part of the original or the adjusted SRISK for regressions with the RRI, but the estimates do not converge in the iterative procedure. Note that when focusing on the positive part of the original or the adjusted SRISK, we lose information on developments in SRISK in negative territory, which makes estimation more difficult.
} 
This paper examines the effects of the TBTF reforms introduced since 2011 using $\triangle \mathrm{CoVaR}$ and SRISK. Examination of these market-based systemic risk measures suggests that the reforms have led to a larger decline in the systemic risk associated with G-SIBs than in that associated with other banks. Further examination suggests that the larger the systemic risk associated with a G-SIB, the more the reforms have led to a decline in its systemic risk. These findings are consistent with the objectives of the reforms and are validated by statistical analyses, including quantile panel regressions. As for SRISK, it is important to adjust for the rapid growth in financial institutions covered by the V-Lab dataset when examining developments in aggregate SRISK over time. Furthermore, SRISK may overestimate systemic risk in recent years by ignoring the role of TLACeligible bonds.

Avenues for future work include updating the analysis in this study once new data become available. One reason is that some of the TBTF reforms were implemented only recently or have not been implemented yet. Although the forward-looking nature of financial markets means that market-based systemic risk measures potentially respond immediately to the announcement of TBTF reforms, it is possible that, to some extent, the response materializes only once such reforms have actually been implemented. Therefore, updating the analysis after further progress in implementation may provide additional insights into this issue. Another reason for updating the analysis at a later time is that the observation period of our dataset (i.e., 2000-2019) does not include a period of financial crisis after the implementation of the TBTF reforms. We therefore focus mainly on a comparison of two non-crisis periods, namely, the period before the global financial crisis (i.e., 2002-2007) and the period after the reforms (i.e., 2012-2019). While this comparison of non-crisis periods is useful, comparing the global financial crisis and a crisis following the reforms would allow us to further examine whether the reforms have had their intended effects. 


\section{References}

Acharya, V., Engle, R., and Richardson, M. (2012). "Capital Shortfall: A New Approach to Ranking and Regulating Systemic Risks," American Economic Review, 102(3), 5964.

Adrian, T., and Brunnermeier, M. K. (2016). "CoVaR," American Economic Review, 106(7), 1705-1741.

BCBS (2013). "Global Systemically Important Banks: Updated Assessment Methodology and the Higher Loss Absorbency Requirement," Bank for International Settlements, July.

BCBS (2019). "An Examination of Initial Experience with the Global Systemically Important Bank Framework," BCBS Working Papers, no 34.

Benoit, S., Colliard, J. E., Hurlin, C., and Pérignon, C. (2017). "Where the Risks Lie: A Survey on Systemic Risk," Review of Finance, 21(1), 109-152.

Bernanke, B. S. (2010). "Causes of the Recent Financial and Economic Crisis," Testimony Before the Financial Crisis Inquiry Commission, Washington DC, September 2, 2010.

Brownlees, C. T., and Engle, R. F. (2017). "SRISK: A Conditional Capital Shortfall Measure of Systemic Risk," Review of Financial Studies, 30(1), 48-79.

Brunnermeier, M. K., Rother, S., and Schnabel, I. (2020). "Asset Price Bubbles and Systemic Risk," Review of Financial Studies, 33, 4272-4317.

Engle, R., and Ruan, T., (2019). "Measuring the Probability of Financial Crisis," Proceedings of the National Academy of Sciences, 116(387), 18341-18346.

FSB (2011). "Key Attributes of Effective Resolution Regimes for Financial Institutions," Financial Stability Board, October.

FSB (2015). "Principles on Loss-absorbing and Recapitalisation Capacity of G-SIBs in Resolution and Total Loss-absorbing Capacity (TLAC) Term Sheet," Financial Stability Board, November. 
FSB (2019). "Resolution Report: Eighth Report on the Implementation of Resolution Reforms: 'Mind the Gap'," Financial Stability Board, November.

FSB (2020). "Evaluation of the Effects of Too-big-to-fail Reforms: Consultation Report," Financial Stability Board, June.

Hirakata, N., Kido, Y., and Thum, J. L. (2020). "Systemic Risk and the Fallacy of Composition: Empirical Evidence from Japanese Regional Bank," International Journal of Central Banking, 16(4), 293-325.

Powell, D. (2016). "Quantile Regression with Nonadditive Fixed Effects," available at: http://works.bepress.com/david_powell/1/.

Sarin N. R., and Summers, L. H. (2016). "Understanding Bank Risk Through Market Measures," Brookings Papers on Economic Activity. 
Table 1: Results of Baseline Regressions with Time Dummies

\begin{tabular}{|c|c|c|c|c|}
\hline & $\Delta \mathrm{CoVaR}$ & SRISK & $\begin{array}{l}\text { SRISK minus } \\
\text { half of TLAC }\end{array}$ & $\begin{array}{l}\text { SRISK minus } \\
\text { TLAC }\end{array}$ \\
\hline $\begin{array}{l}\text { Tech bubble and burst } \\
\text { (2000-2001) }\end{array}$ & $\begin{array}{l}0.4957 * \\
(0.2650)\end{array}$ & $\begin{array}{l}-0.0247 * * * \\
(0.0066)\end{array}$ & $\begin{array}{l}-0.0123^{*} \\
(0.0065)\end{array}$ & $\begin{array}{c}0.0001 \\
(0.0075)\end{array}$ \\
\hline $\begin{array}{c}\text { Pre-crisis } \\
(2002-2007)\end{array}$ & $\begin{array}{l}0.3022^{* * *} \\
(0.1049)\end{array}$ & $\begin{array}{l}-0.0055 \\
(0.0045)\end{array}$ & $\begin{array}{l}0.0052 \\
(0.0051)\end{array}$ & $\begin{array}{l}0.0159^{* *} \\
(0.0066)\end{array}$ \\
\hline $\begin{array}{c}\text { Crisis } \\
(2008-2009)\end{array}$ & $\begin{array}{l}0.6548 * \\
(0.3775)\end{array}$ & $\begin{array}{c}0.0018 \\
(0.0048)\end{array}$ & $\begin{array}{l}0.0114^{* *} \\
(0.0047)\end{array}$ & $\begin{array}{l}0.0209 * * * \\
(0.0055)\end{array}$ \\
\hline $\begin{array}{l}\text { Post-crisis but pre-reform } \\
\qquad(2010-2011)\end{array}$ & $\begin{array}{l}0.4242 * * \\
(0.1880)\end{array}$ & $\begin{array}{l}-0.0011 \\
(0.0034)\end{array}$ & $\begin{array}{l}0.0077 * * \\
(0.0033)\end{array}$ & $\begin{array}{l}0.0165^{* * * *} \\
(0.0043)\end{array}$ \\
\hline $\begin{array}{c}\text { Number of observations } \\
\text { Number of banks }\end{array}$ & $\begin{array}{c}4,564 \\
237\end{array}$ & $\begin{array}{c}4,950 \\
326\end{array}$ & $\begin{array}{c}4,950 \\
326\end{array}$ & $\begin{array}{c}4,950 \\
326\end{array}$ \\
\hline
\end{tabular}

Note: This table reports the estimation results for the interaction term between the G-SIB dummy and the time dummy in the baseline regressions for the different market-based systemic risk measures, i.e., $\triangle$ CoVaR, SRISK, SRISK minus half of TLAC debt, and SRISK minus all TLAC debt. The latter three are normalized by the annual average of total assets. The four time dummies correspond to the period of the tech bubble and its burst (2000-2001), the period before the global financial crisis (20022007), the period of the global financial crisis (2008-2009), and the post-crisis-but-pre-reform period (2010-2011). The post TBTF reform period (2012-2019) acts as the reference category. ***,**, and * denote statistical significance at 1,5 , and 10 percent levels, respectively. 
Table 2: Results of Baseline Regressions with a Different Definition of the Time Dummies

\begin{tabular}{|c|c|c|c|c|}
\hline & $\Delta \mathrm{CoVaR}$ & SRISK & $\begin{array}{l}\text { SRISK minus } \\
\text { half of TLAC }\end{array}$ & $\begin{array}{l}\text { SRISK minus } \\
\text { TLAC }\end{array}$ \\
\hline $\begin{array}{l}\text { Tech bubble and burst } \\
\qquad(2000-2001)\end{array}$ & $\begin{array}{c}0.4276 \\
(0.2847)\end{array}$ & $\begin{array}{l}-0.0239 * * * \\
(0.0071)\end{array}$ & $\begin{array}{l}-0.0049 \\
(0.0070)\end{array}$ & $\begin{array}{l}0.0141 \\
(0.0089)\end{array}$ \\
\hline $\begin{array}{c}\text { Pre-crisis } \\
(2002-2007)\end{array}$ & $\begin{array}{l}0.2289 * * \\
(0.1041)\end{array}$ & $\begin{array}{l}-0.0046 \\
(0.0050)\end{array}$ & $\begin{array}{l}0.0127 * * \\
(0.0059)\end{array}$ & $\begin{array}{l}0.0299 * * * \\
(0.0084)\end{array}$ \\
\hline $\begin{array}{c}\text { Crisis } \\
(2008-2009)\end{array}$ & $\begin{array}{c}0.6136 \\
(0.3784)\end{array}$ & $\begin{array}{l}0.0027 \\
(0.0052)\end{array}$ & $\begin{array}{l}0.0189 * * * \\
(0.0052)\end{array}$ & $\begin{array}{l}0.035^{* * * *} \\
(0.0071)\end{array}$ \\
\hline $\begin{array}{l}\text { Post-crisis but pre-reform } \\
\qquad \underline{(2010-2015)}\end{array}$ & $\begin{array}{c}0.0236 \\
(0.0921)\end{array}$ & $\begin{array}{c}0.0011 \\
(0.0031)\end{array}$ & $\begin{array}{l}0.0148^{* * * *} \\
(0.0034)\end{array}$ & $\begin{array}{l}0.0285^{* * *} \\
(0.0053)\end{array}$ \\
\hline $\begin{array}{c}\text { Number of observations } \\
\text { Number of banks }\end{array}$ & $\begin{array}{c}4,564 \\
237\end{array}$ & $\begin{array}{c}4,950 \\
326\end{array}$ & $\begin{array}{c}4,950 \\
326\end{array}$ & $\begin{array}{c}4,950 \\
326\end{array}$ \\
\hline
\end{tabular}

Note: This table reports the estimation results for the interaction term between the G-SIB dummy and the time dummy in the baseline regressions for the different market-based systemic risk measures, i.e., $\triangle$ CoVaR, SRISK, SRISK minus half of TLAC debt, and SRISK minus all TLAC debt. The latter three are normalized by the annual average of total assets. The four time dummies correspond to the period of the tech bubble and its burst (2000-2001), the period before the global financial crisis (20022007), the period of the global financial crisis (2008-2009), and the post-crisis-but-pre-reform period (2010-2015). The post TBTF reform period (2016-2019) acts as the reference category. *** and ** denote statistical significance at the 1 and 5 percent levels, respectively. 
Table 3: Results of Alternative Regressions with the Resolution Reform Index

\begin{tabular}{|c|c|c|c|c|}
\hline & $\Delta \mathrm{CoVaR}$ & SRISK & $\begin{array}{l}\text { SRISK minus } \\
\text { half of TLAC }\end{array}$ & $\begin{array}{l}\text { SRISK minus } \\
\text { TLAC }\end{array}$ \\
\hline Original RRI & $\begin{array}{l}-0.3821 \\
(0.2952)\end{array}$ & $\begin{array}{l}-0.0037 \\
(0.0077)\end{array}$ & $\begin{array}{l}-0.0314 * * * \\
(0.0088)\end{array}$ & $\begin{array}{l}-0.059 * * * \\
(0.0131)\end{array}$ \\
\hline $\begin{array}{l}\text { Extrapolated (1): RRI assumed } \\
\text { to be zero before } 2010\end{array}$ & $\begin{array}{l}-0.521 * * * \\
(0.1416)\end{array}$ & $\begin{array}{c}0.0096 \\
(0.0068)\end{array}$ & $\begin{array}{l}-0.0118 \\
(0.0076)\end{array}$ & $\begin{array}{l}-0.0331 * * * \\
(0.0098)\end{array}$ \\
\hline $\begin{array}{l}\text { Extrapolated (2): RRI assumed } \\
\text { to be the same as in } 2010\end{array}$ & $\begin{array}{l}-0.7345^{* * *} \\
(0.2637)\end{array}$ & $\begin{array}{c}0.0053 \\
(0.0087)\end{array}$ & $\begin{array}{l}-0.0214 * * \\
(0.0093)\end{array}$ & $\begin{array}{l}-0.0481 * * * \\
(0.0134)\end{array}$ \\
\hline
\end{tabular}

Note: This table reports the estimation results for the interaction term between the G-SIB dummy and the Resolution Reform Index (RRI) for different combinations of the market-based systemic risk measures and the RRIs. The columns show the market-based systemic risk measure in question, i.e., $\triangle$ CoVaR, SRISK, SRISK minus half of TLAC debt, and SRISK minus all TLAC debt. The latter three are normalized by the annual average of total assets. The rows show the RRI used, i.e., the original RRI, the extrapolated RRI assuming that it was zero before 2010, and the extrapolated RRI assuming that it takes the same value before 2010 as in $2010 . * * *$ and $* *$ denote statistical significance at the 1 and 5 percent levels, respectively. 
Figure 1: Aggregate $\Delta \mathrm{CoVaR}$

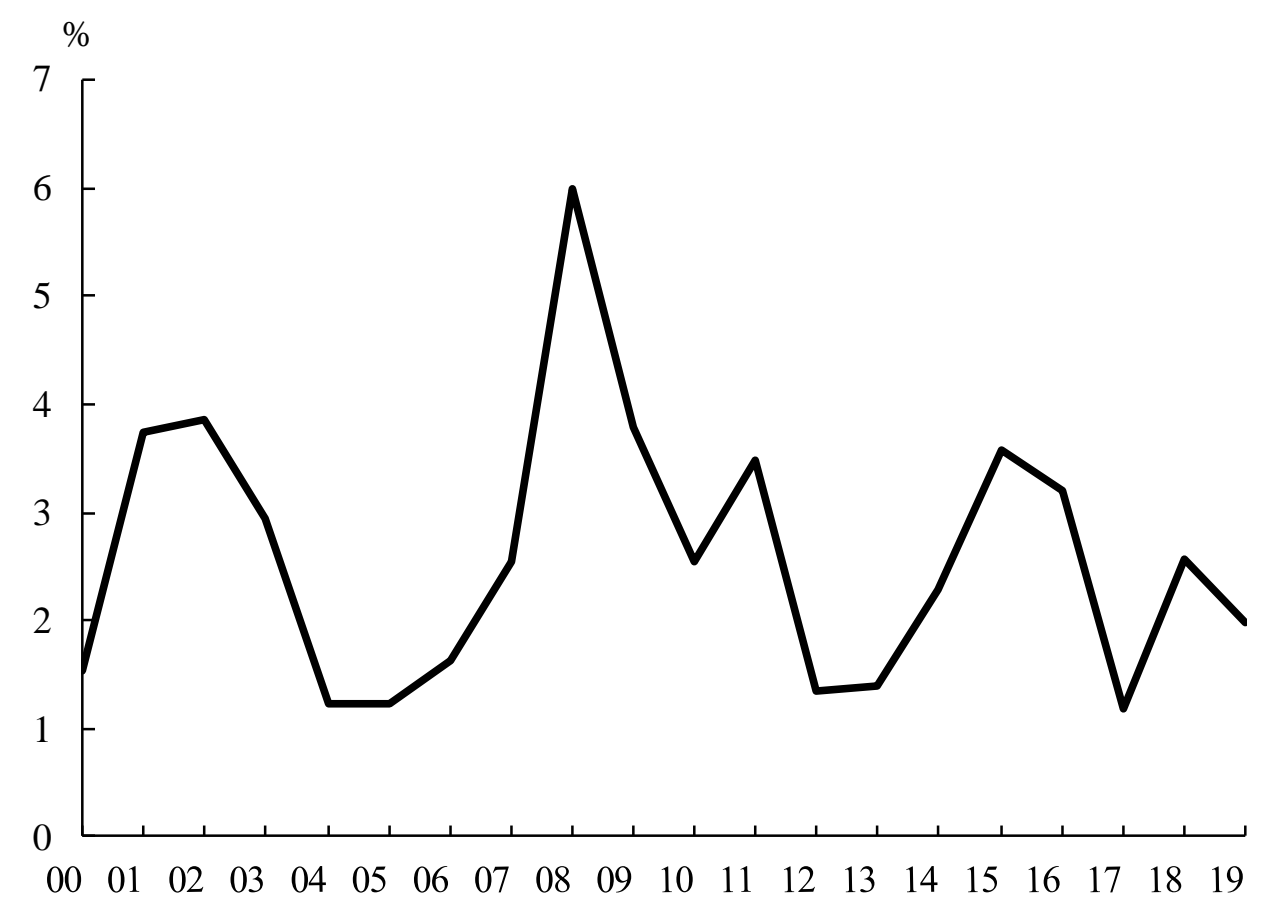

Note: The figure plots the aggregate $\Delta \mathrm{CoVaR}$, i.e., the weighted average of the $\Delta \mathrm{CoVaR}$ of all individual financial institutions using financial institutions' market capitalization as weights. 
Figure 2: Distribution of $\Delta \mathrm{CoVaR}$ of Individual Financial Institutions

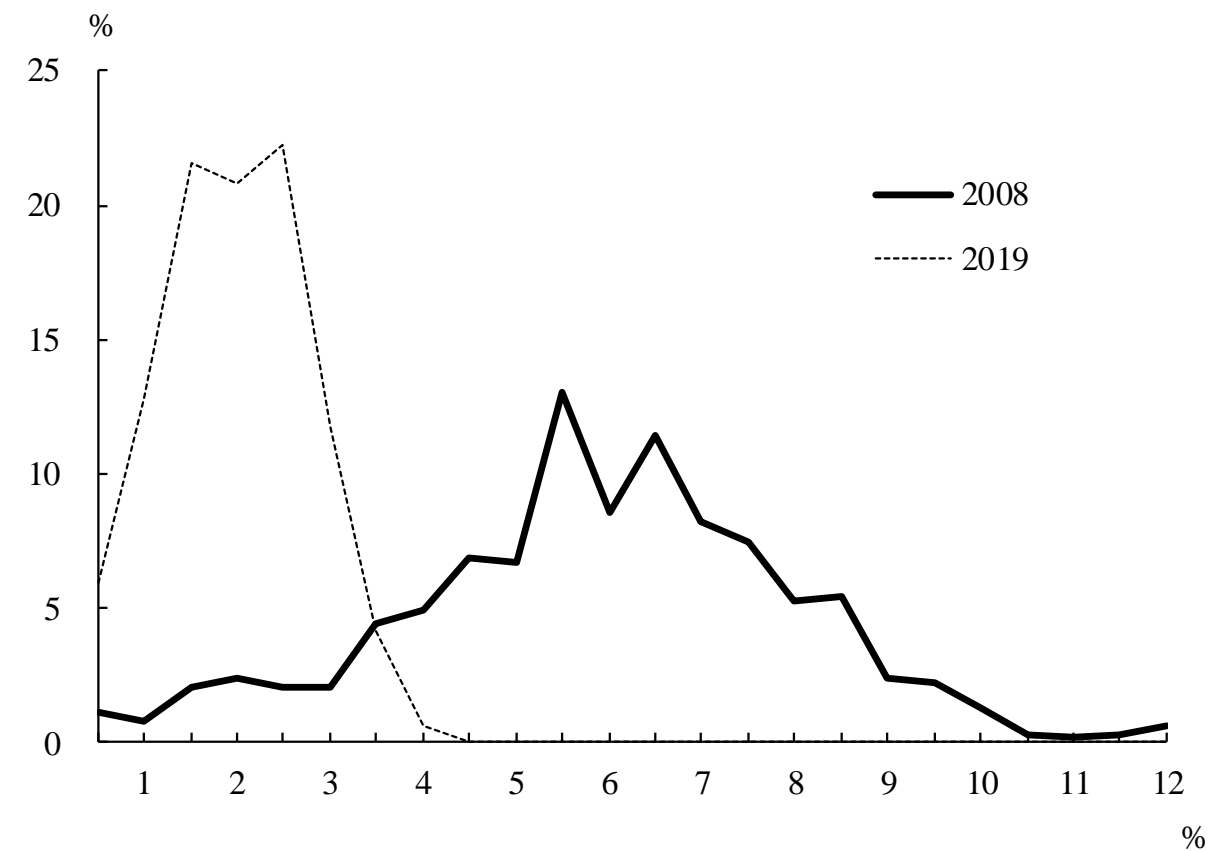

Note: The figure shows the distribution of the $\Delta$ CoVaR of individual financial institutions in 2008 (solid line) and 2019 (broken line). 
Figure 3: $\Delta$ CoVaR by Region and Sector

(a) $\triangle \mathrm{CoVaR}$ by region

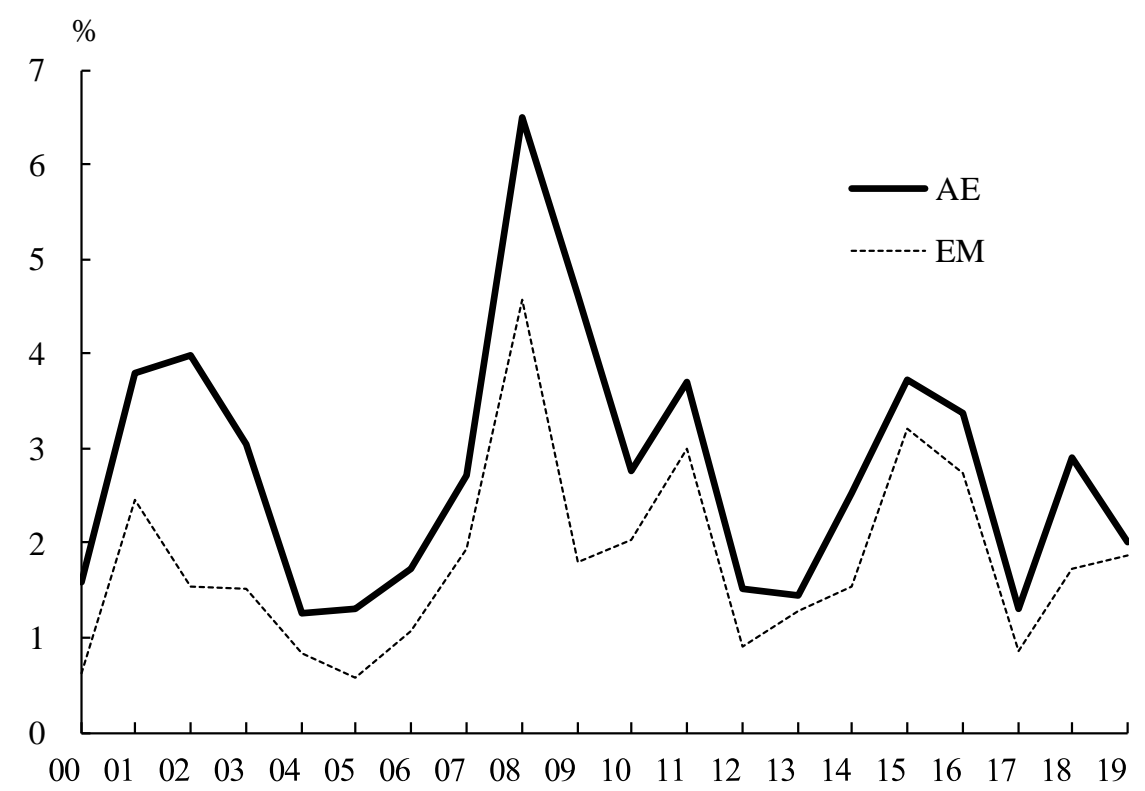

(b) $\triangle \mathrm{CoVaR}$ in the pre-crisis and post-reform periods by region and sector

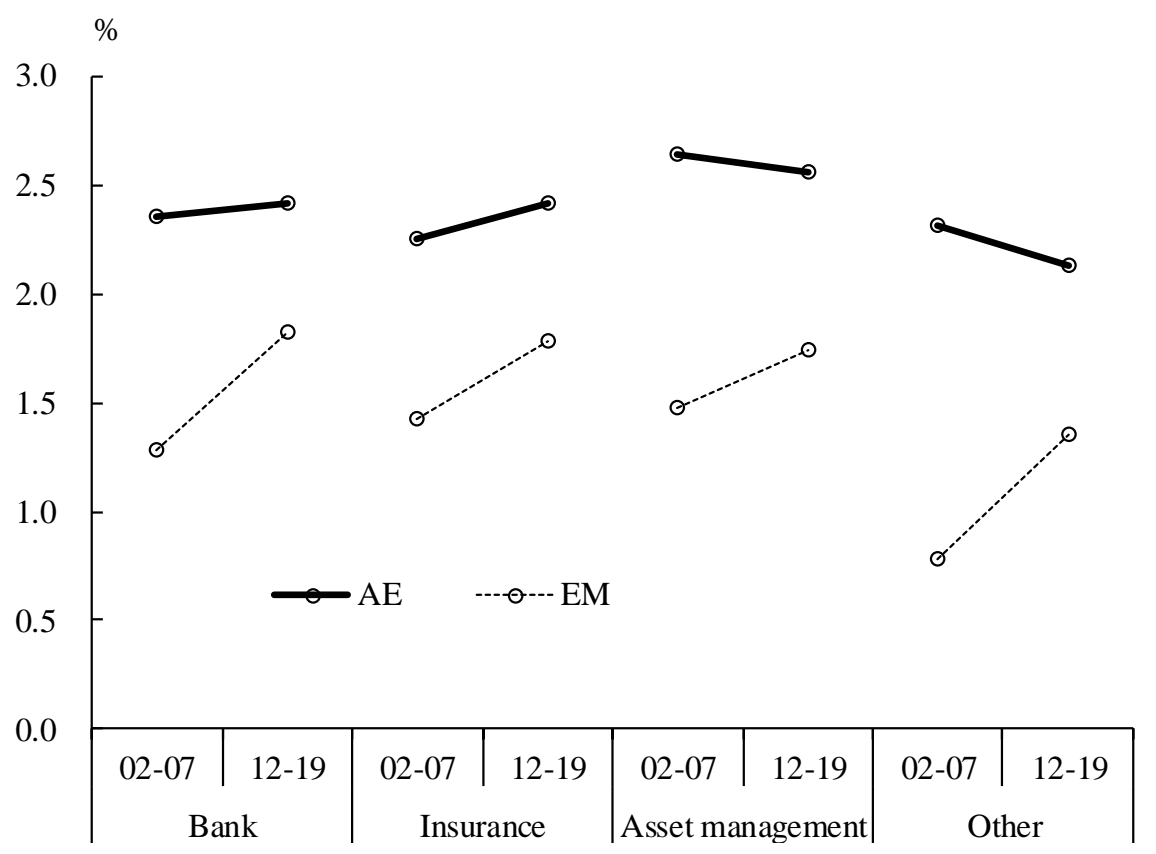

Note: Panel (a) plots the aggregate $\Delta$ CoVaR for advanced economies (AE, solid line) and emerging markets (EM, broken line). Panel (b) plots the aggregate $\Delta$ CoVaR for AE (solid line) and EM (broken line) for the pre-crisis period (2002-2007) and the post-reform period (2012-2019) by sector (bank, insurance, asset management, and other). 
Figure 4: $\triangle \mathrm{CoVaR}$ of G-SIBs and Other Banks

(a) $\triangle$ CoVaR by bank type

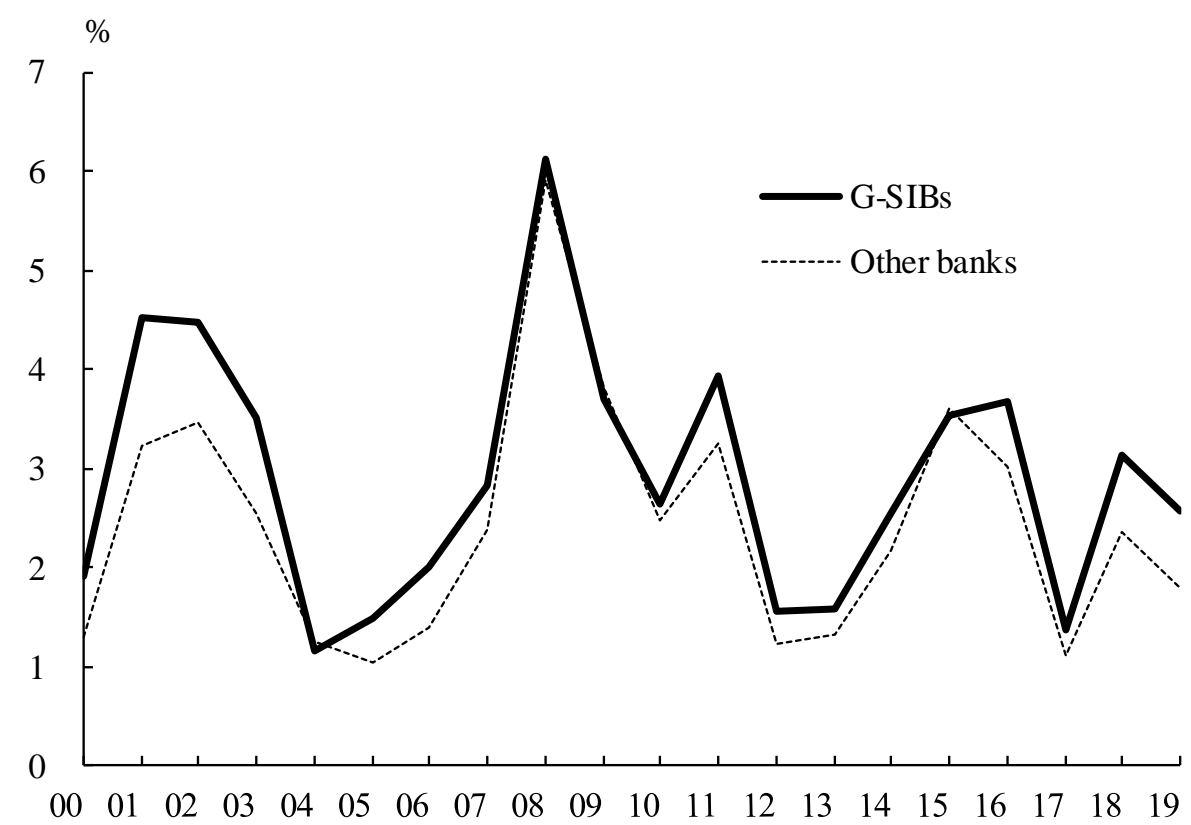

(b) Change in distribution of $\Delta \mathrm{CoVaR}$

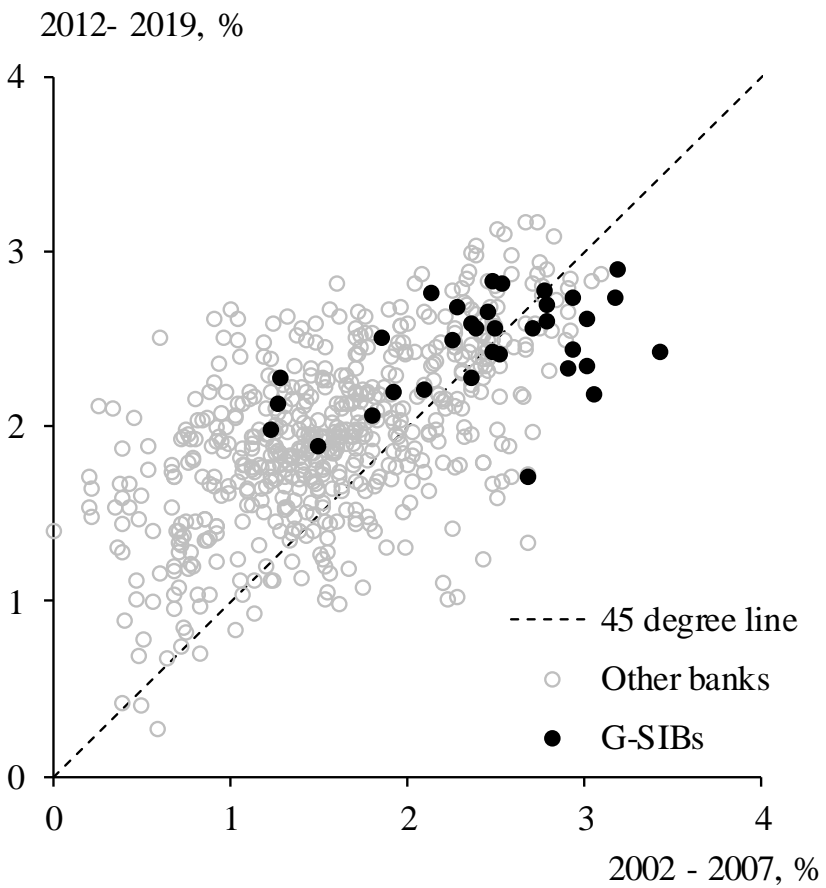

Note: Panel (a) plots the aggregate $\Delta \mathrm{CoVaR}$ for G-SIBs and other banks. In Panel (b), the horizontal axis represents the pre-crisis period (2002-2007) and the vertical axis the post-reform period (20122019). Each black circle corresponds to a G-SIB while each white circle corresponds to a bank that is not a G-SIB. 
(a) Original SRISK

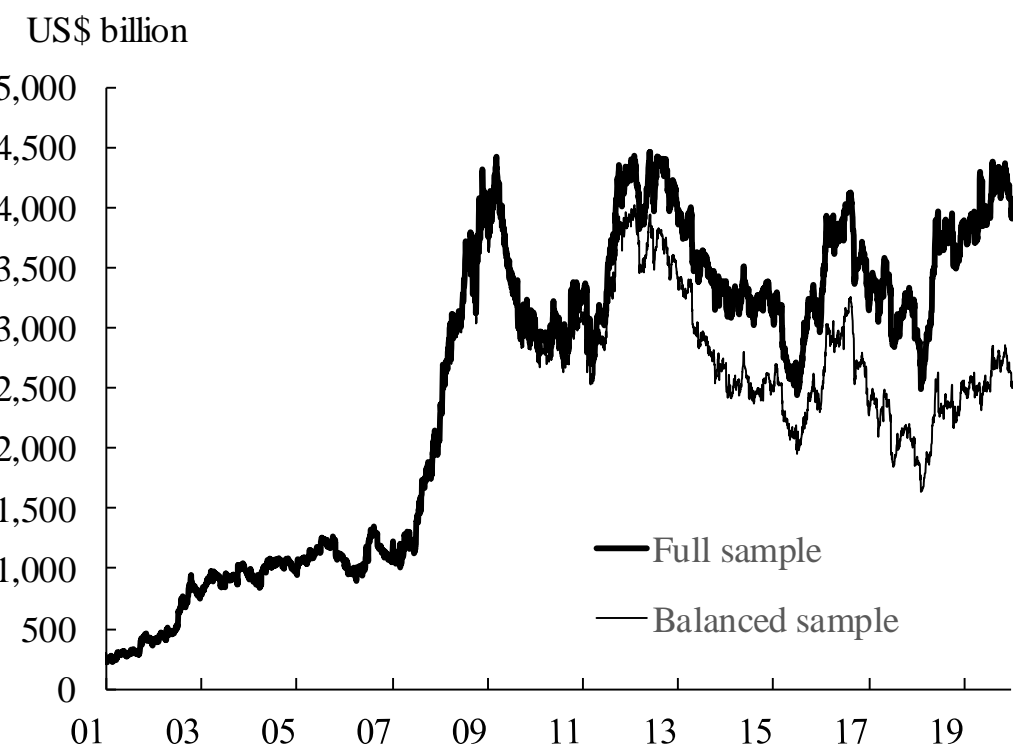

(b) SRSIK to GDP

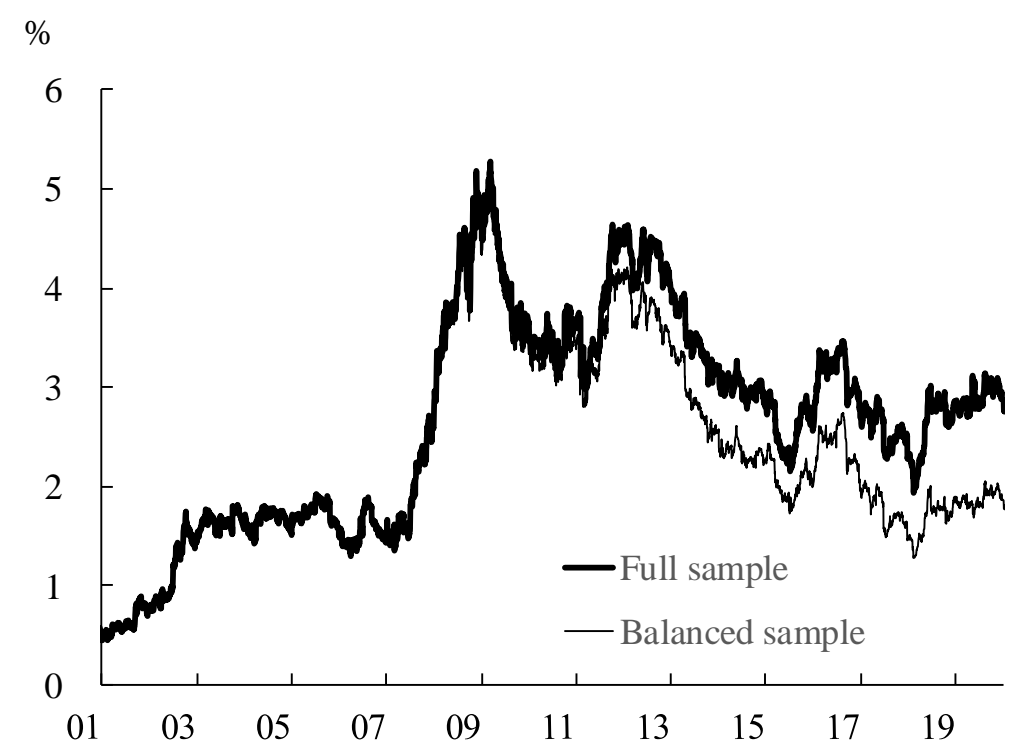

Note: Panels (a) and (b) plot the aggregate SRISK for all institutions in the sample and its ratio to global GDP, respectively. Both panels plot the results with the full sample (fat line) and the balanced sample (thin line). The balanced sample covers only institutions that have remained in the sample since 2007. 
Figure 6: SRISK by Region

(a) Full sample

US\$ billion

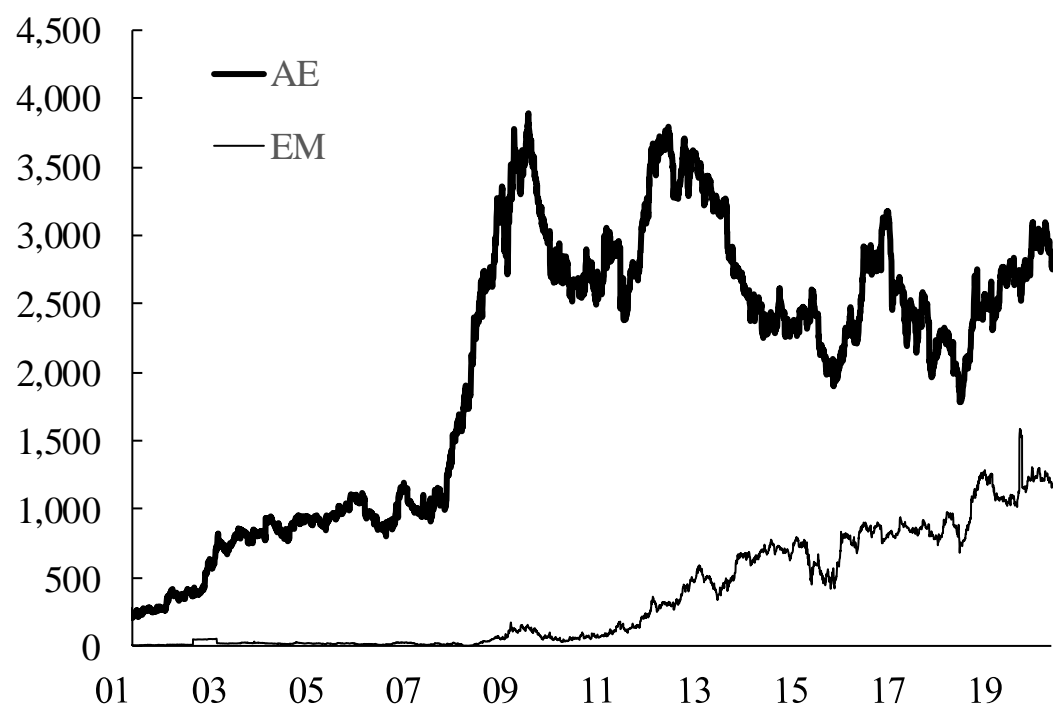

(b) Balanced sample (as \% of GDP)

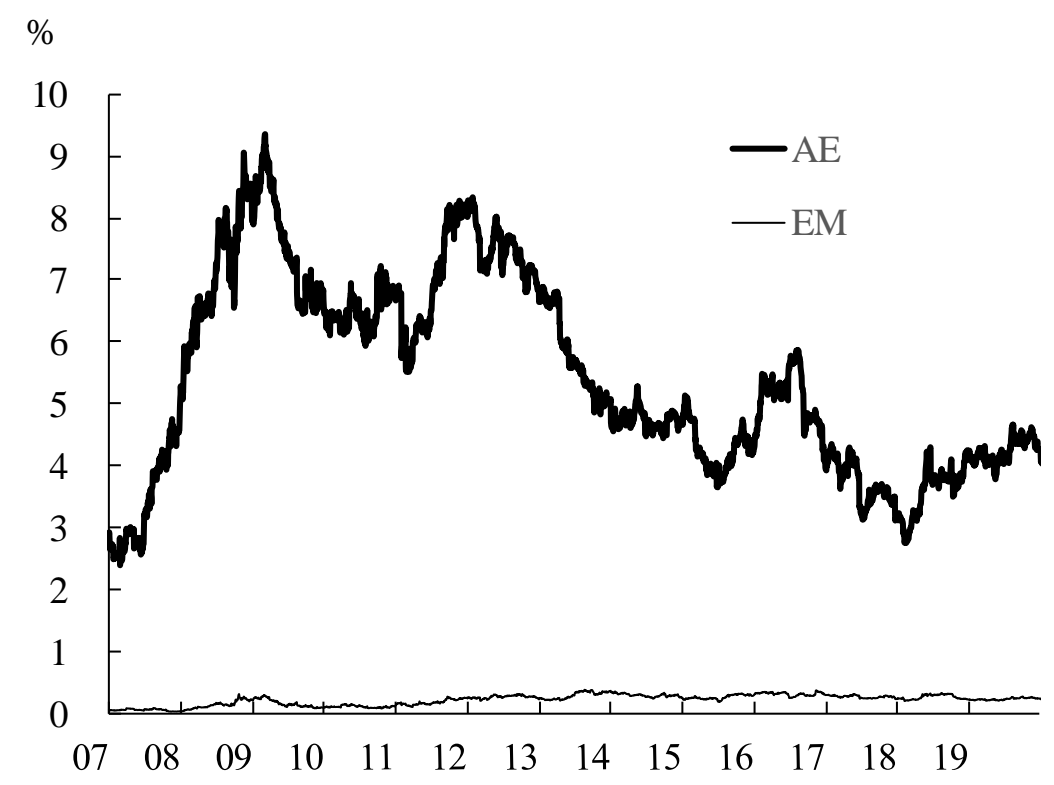

Note: Panels (a) and (b) plot the aggregate SRISK based on the full sample and the SRISK-to-GDP ratio based on the balanced sample, respectively, for advanced economies (AE, fat line) and emerging markets (EM, thin line). The balanced sample covers only institutions that have remained in the sample since 2007. 
Figure 7: SRISK-to-GDP Ratio by Region and Sector for the Balanced Sample

(a) Advanced economies

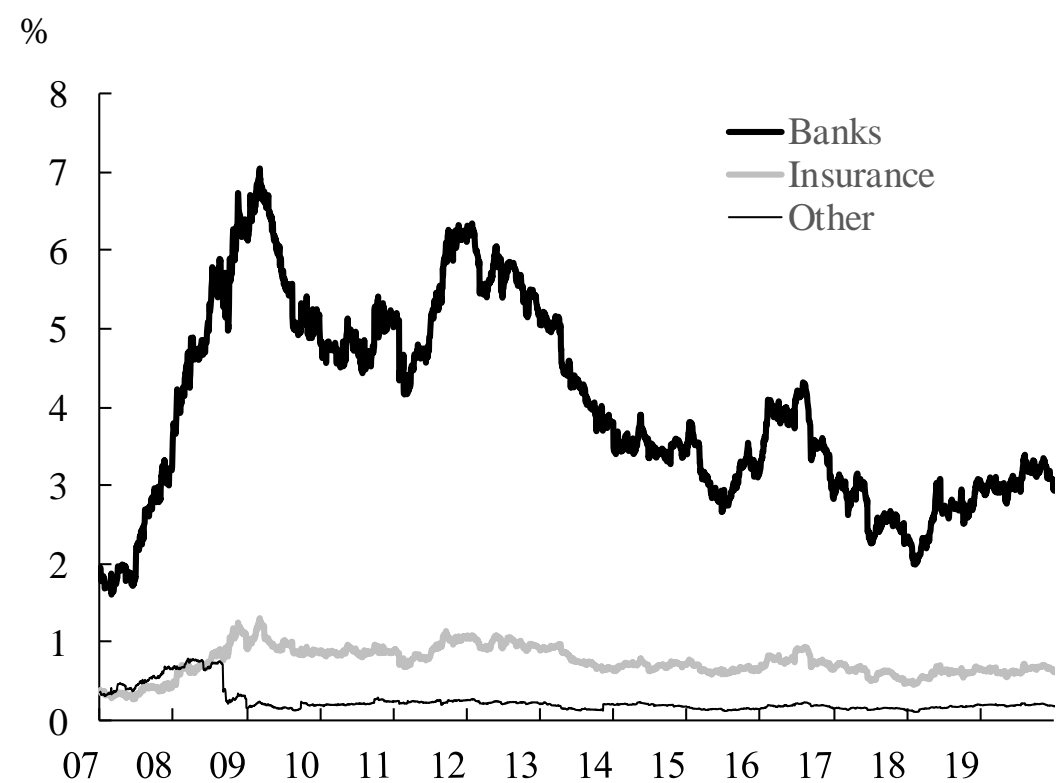

(b) Emerging markets

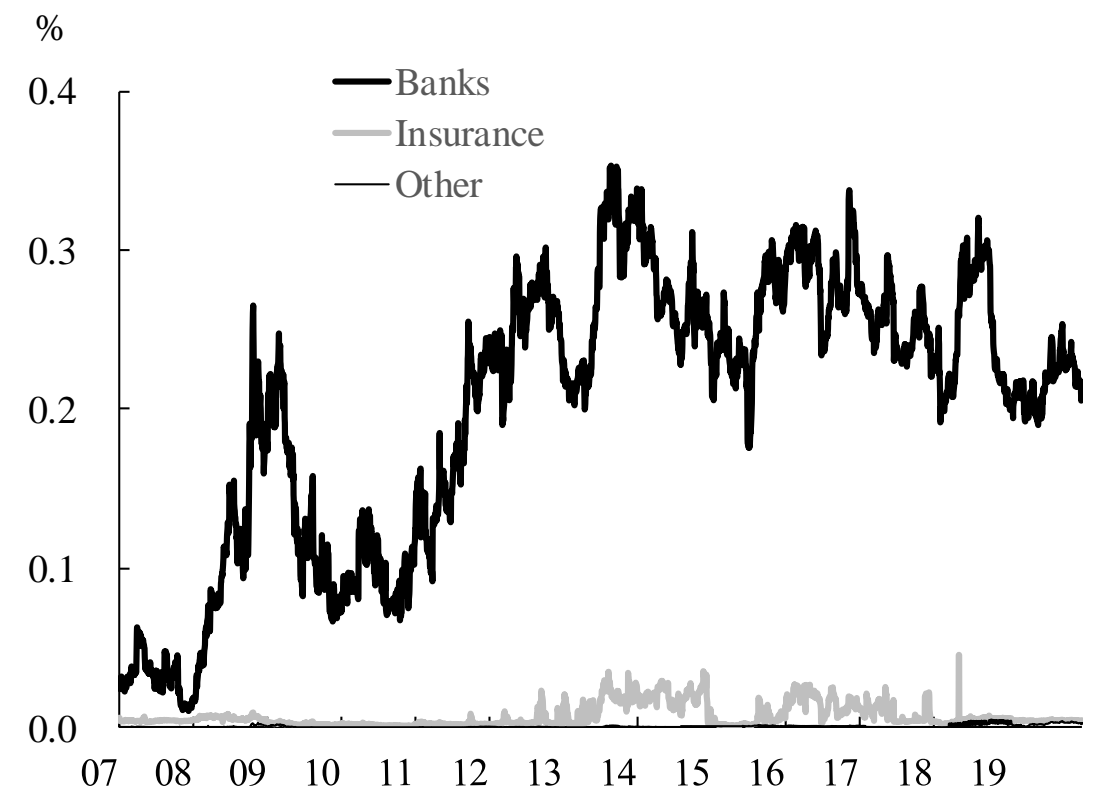

Note: Panels (a) and (b) plot the aggregate SRISK to global GDP based on the balanced sample for advanced economies and emerging markets, respectively, by sector, consisting of banks (fat line), insurance companies (grey line), and other financial institutions (thin line). The balanced sample covers only institutions that have remained in the sample since 2007. 
Figure 8: SRISK within Banking Sector

(a) Full sample

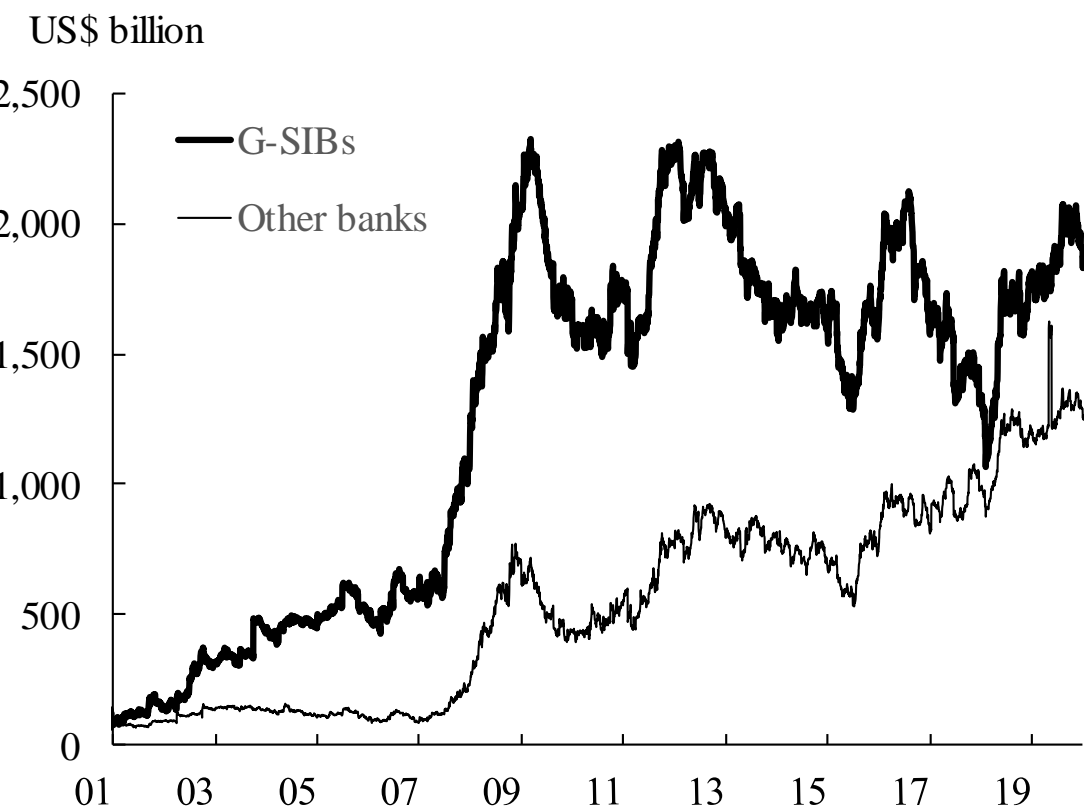

(b) Balanced sample (as \% of GDP)

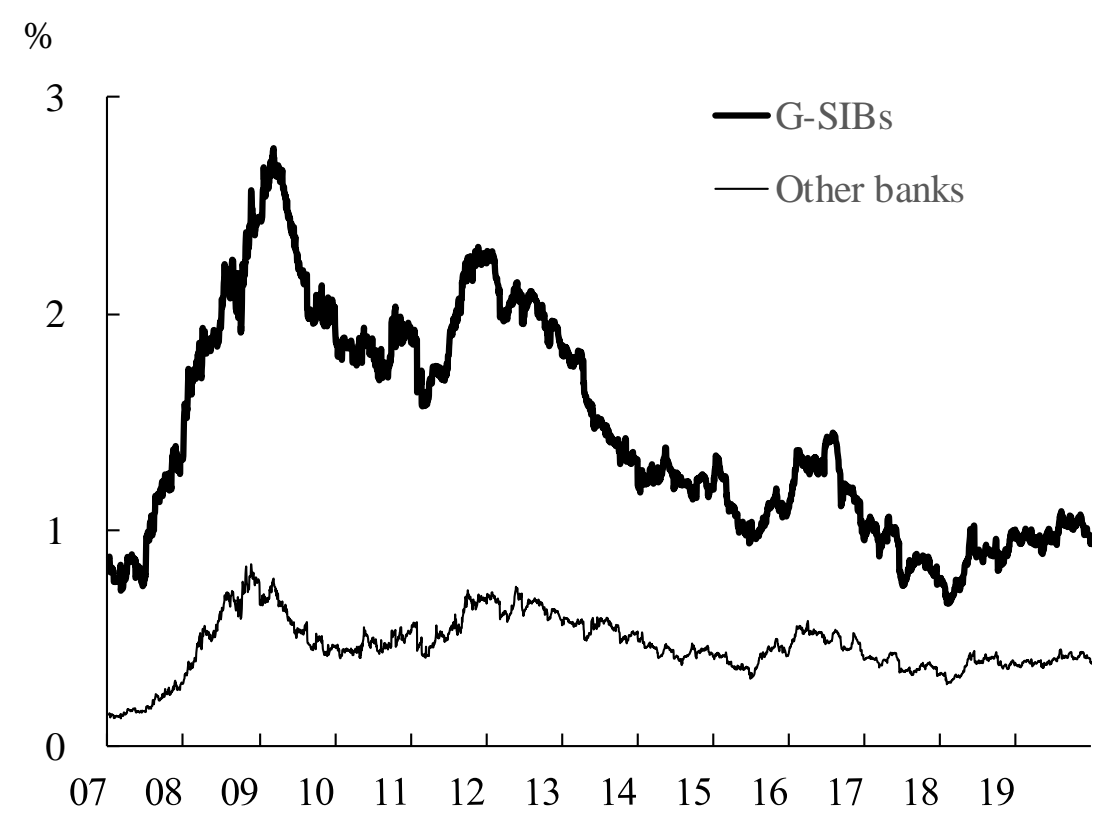

Note: Panels (a) and (b) plot the aggregate SRISK based on the full sample and the SRISK-to-GDP ratio based on the balanced sample, respectively, for G-SIBs (fat line) and other banks (thin line). The balanced sample covers only institutions that have remained in the sample since 2007. 
Figure 9: SRISK Adjusted for TLAC-eligible Debt

(a) All financial institutions

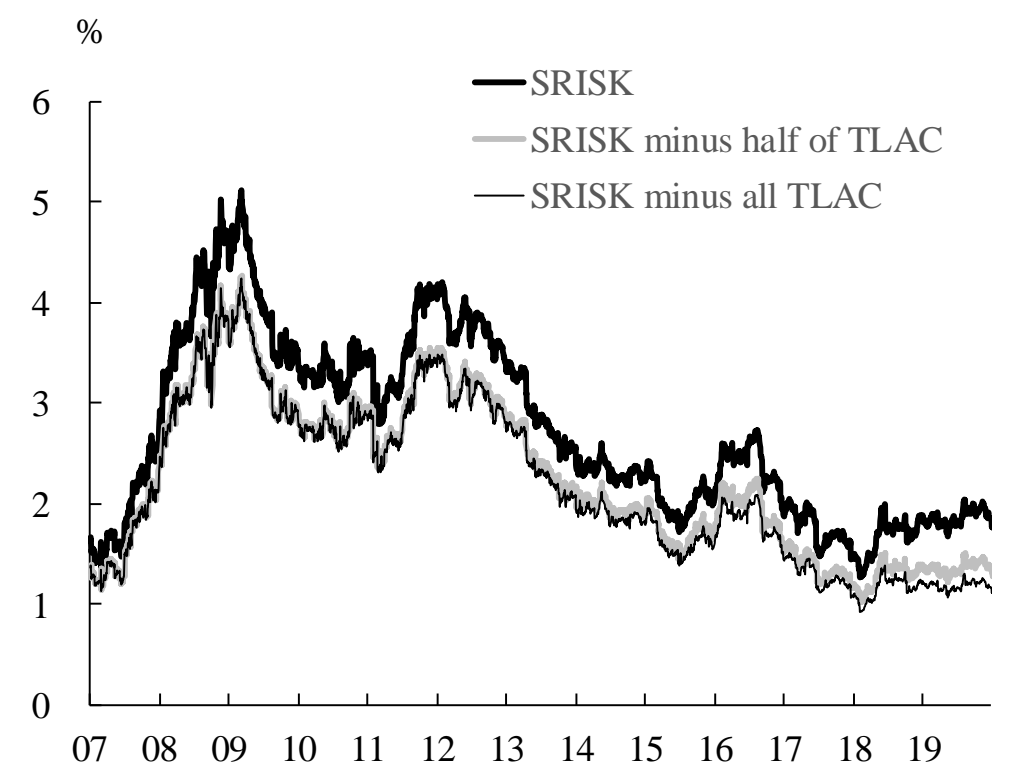

(b) G-SIBs

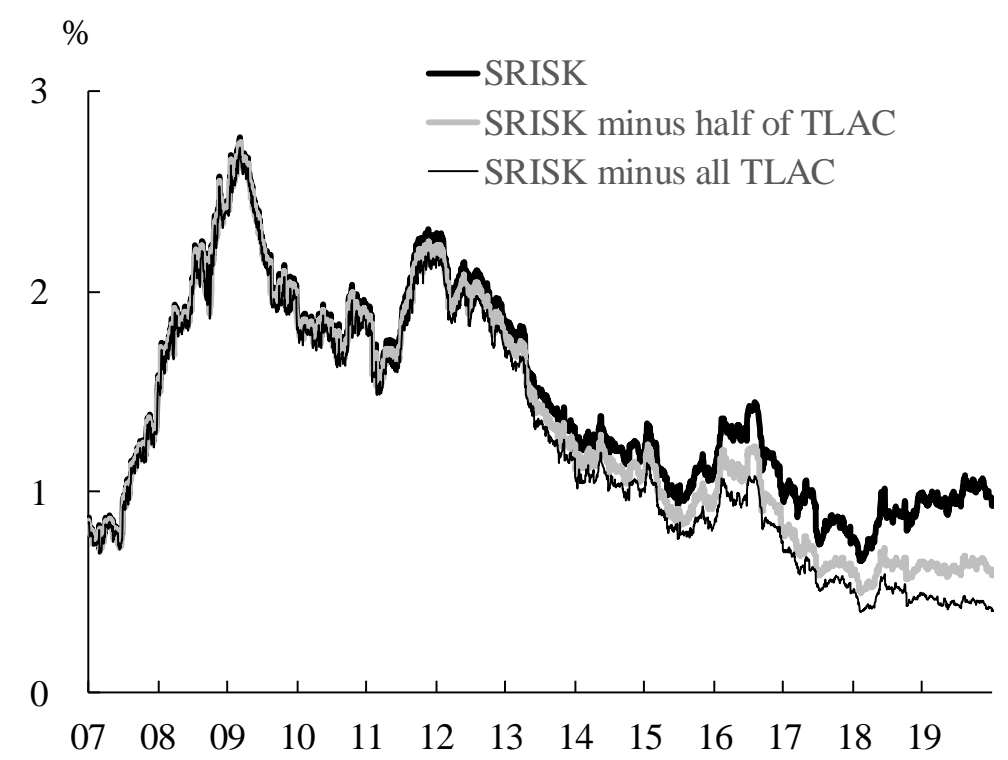

Note: Panel (a) plots the aggregate SRISK-to-world-GDP ratio for all institutions based on the balanced sample. Panel (b) plots the same ratio for G-SIBs. In both panels, the thick grey line and the thin line use SRISK minus half of TLAC debt and SRISK minus all TLAC debt, respectively, instead of SRISK (fat line). The balanced sample covers only institutions that have remained in the sample since 2007. 
Figure 10: Distribution of G-SIB SRISK

(a) SRISK

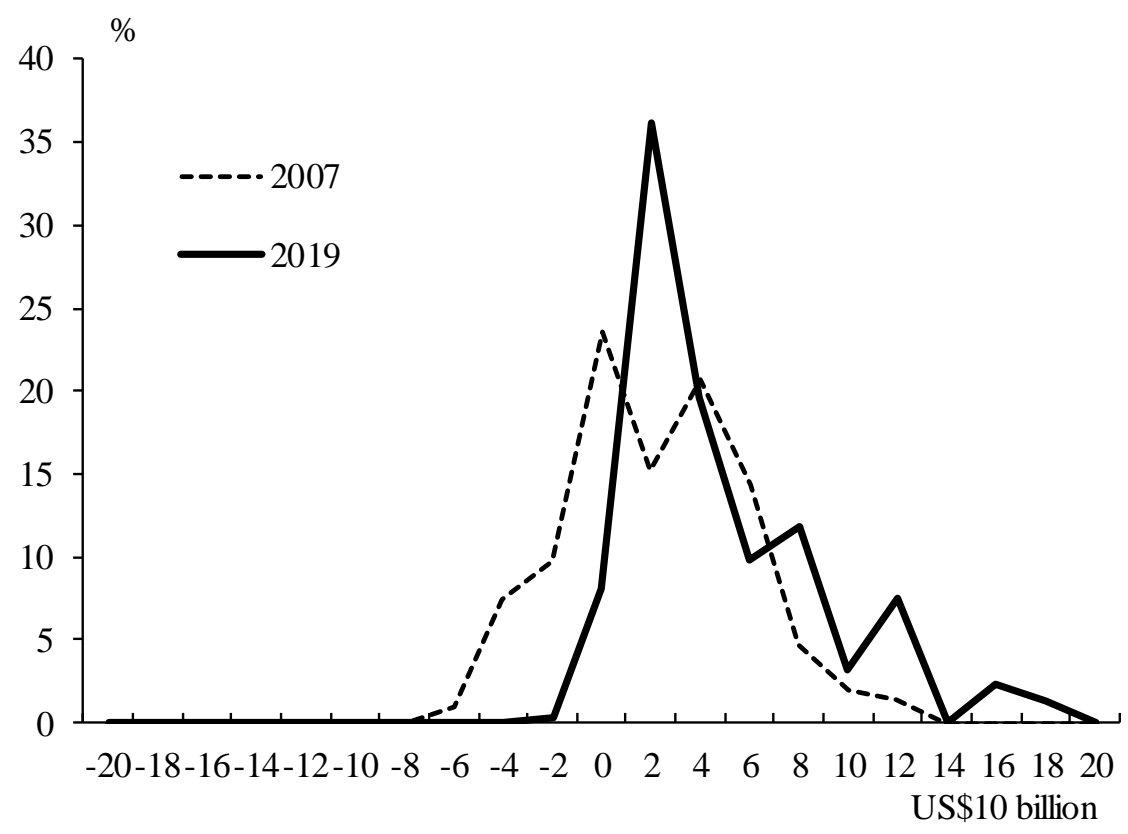

(b) SRISK minus all TLAC debt

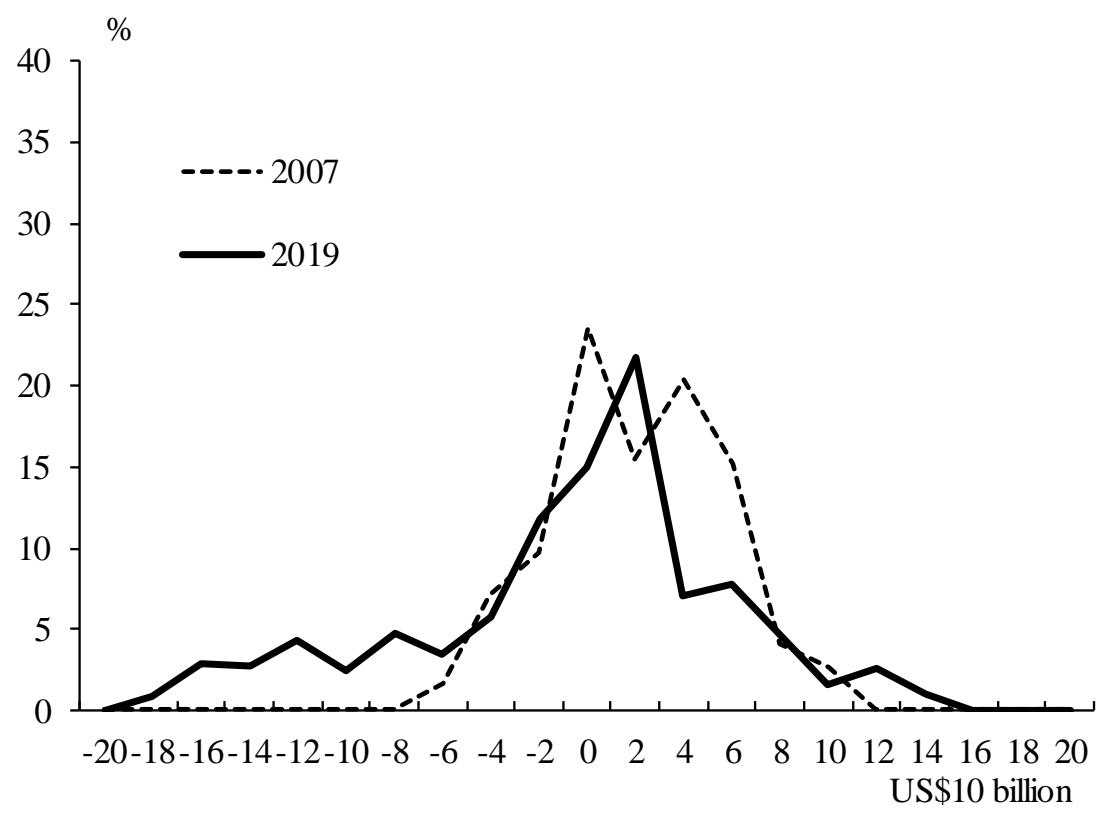

Note: Panels (a) and (b) in the figure show the distributions of SRISK and SRISK minus all TLAC debt, respectively, of individual G-SIBs in 2007 (broken line) and 2019 (solid line). 
Figure 11: Resolution Reform Index

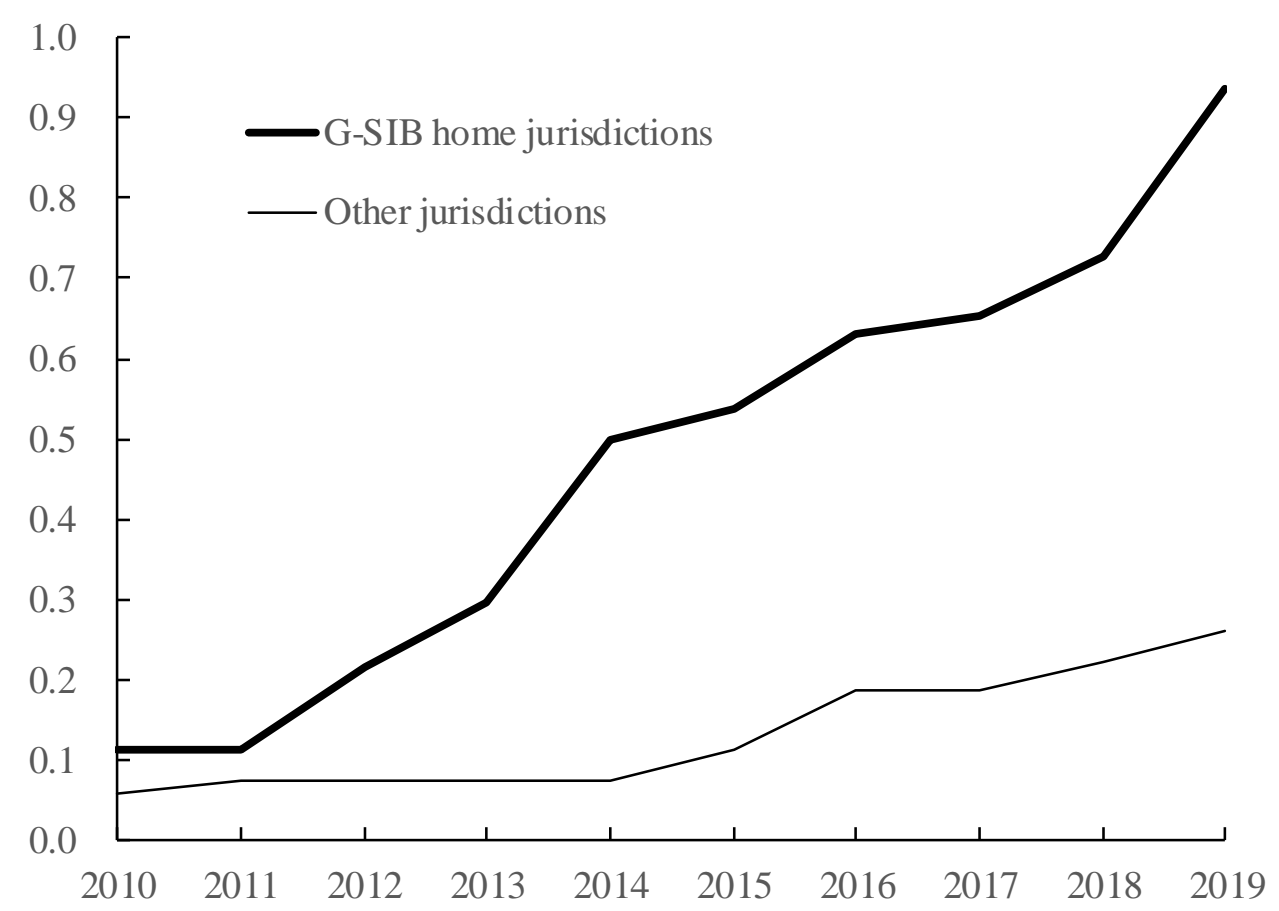

Note: The figure plots the medians of the Resolution Reform Index, which is constructed by the FSB, for G-SIB home jurisdictions (fat line) and other jurisdictions (thin line). 
Figure 12: Results of Quantile Panel Regressions with Time Dummies: Coefficient of the Interaction Term between the G-SIB Dummy and the Pre-crisis Dummy

(a) $\triangle \mathrm{CoVaR}$

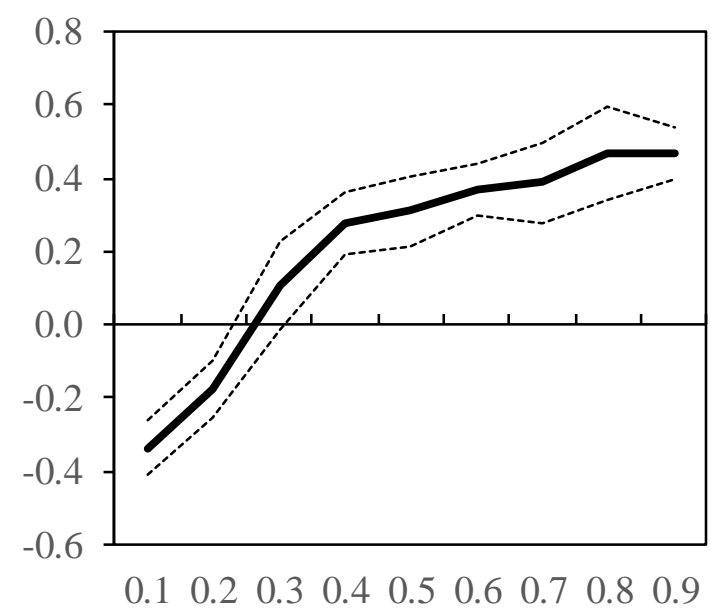

(c) SRISK minus half of TLAC

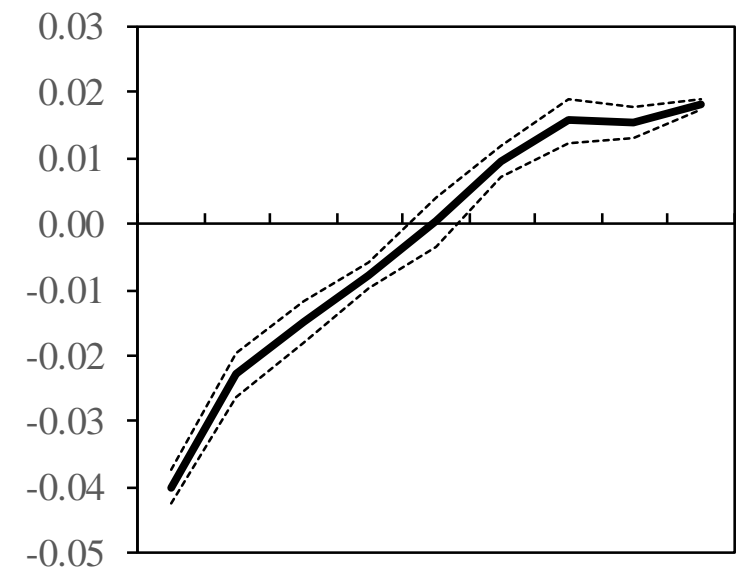

$\begin{array}{lllllllllllll}0.1 & 0.2 & 0.3 & 0.4 & 0.5 & 0.6 & 0.7 & 0.8 & 0.9\end{array}$ (b) SRISK

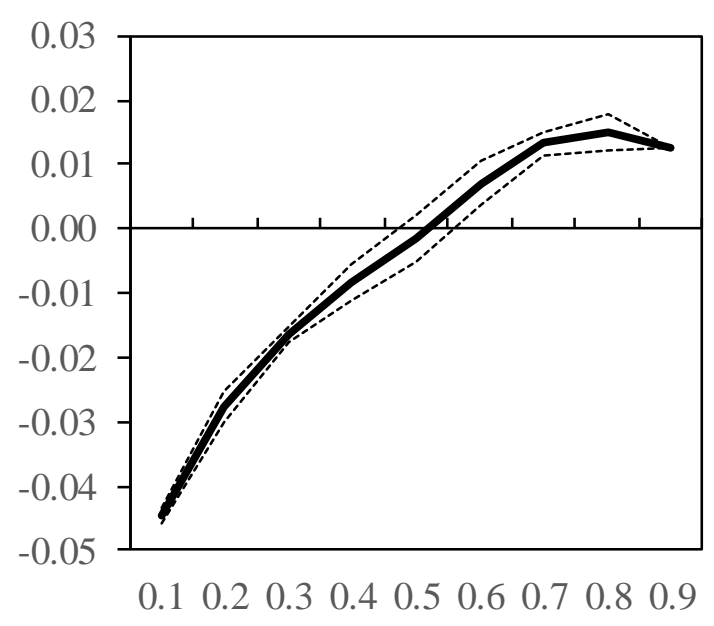

(d) SRISK minus all TLAC

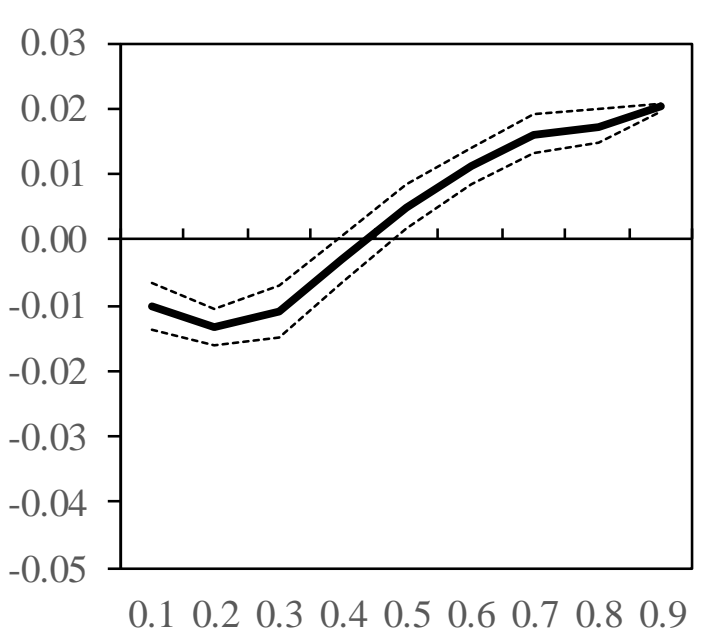

Note: Panels (a), (b), (c), and (d) show the estimation results of quantile panel regressions with time dummies for $\Delta$ CoVaR, SRISK, SRISK minus half of TLAC debt, and SRISK minus all TLAC debt, respectively. The latter three are normalized by the annual average of total assets. The horizontal axes show the quantiles. The solid lines represent the coefficient on the interaction term between the G-SIB dummy and the pre-crisis dummy. The broken lines represent the $90 \%$ confidence intervals. 
Figure 13: Results of Quantile Panel Regressions with Resolution Reform Index: Coefficient of Interaction Term between the G-SIB Dummy and the Extrapolated RRI

(a) $\triangle \mathrm{CoVaR}$

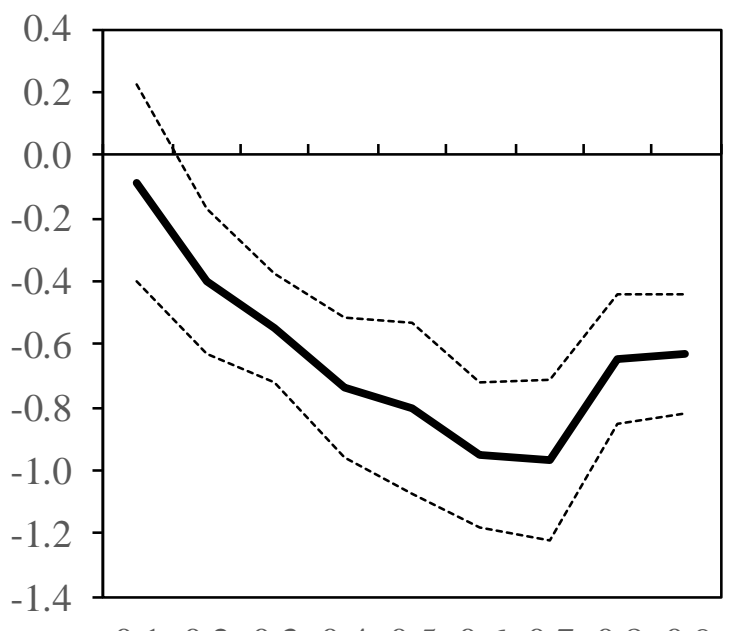

$\begin{array}{lllllllll}0.1 & 0.2 & 0.3 & 0.4 & 0.5 & 0.6 & 0.7 & 0.8 & 0.9\end{array}$ (b) SRISK

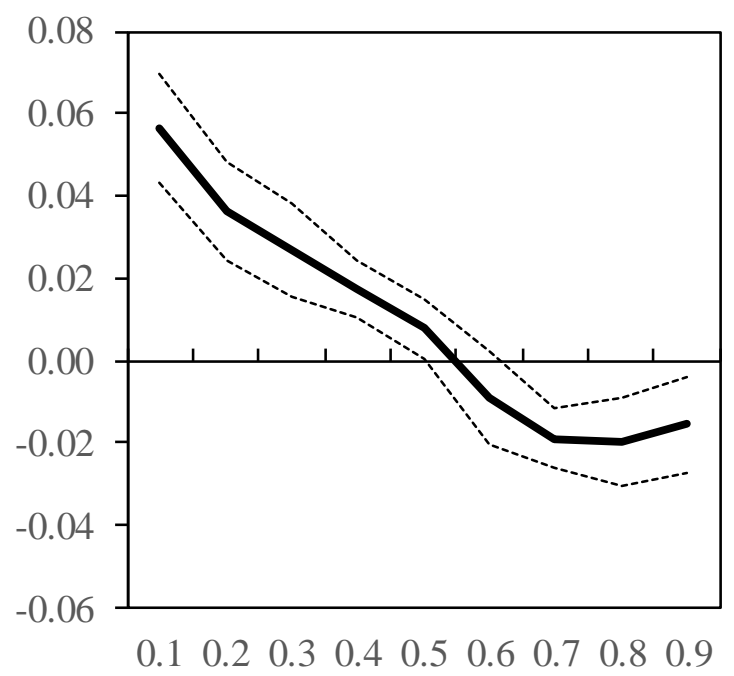

(d) SRISK minus all TLAC

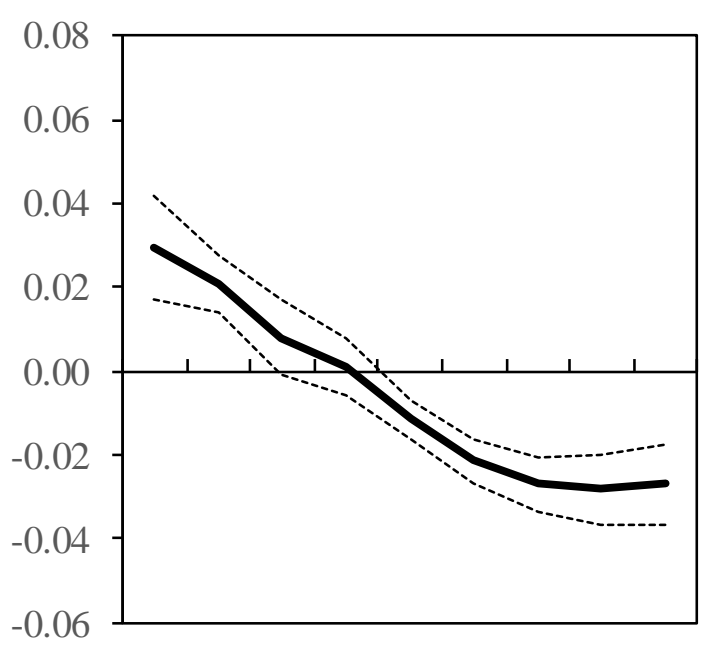

$\begin{array}{llllllllllll}0.1 & 0.2 & 0.3 & 0.4 & 0.5 & 0.6 & 0.7 & 0.8 & 0.9\end{array}$

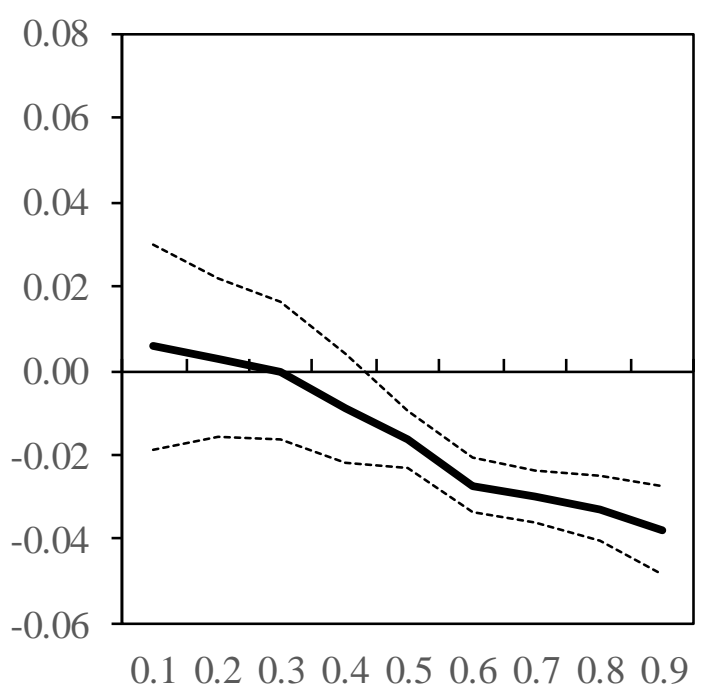

Note: Panels (a), (b), (c), and (d) show the estimation results of quantile panel regressions with the Resolution Reform Index (RRI) for $\Delta$ CoVaR, SRISK, SRISK minus half of TLAC debt, and SRISK minus all TLAC debt, respectively. The latter three are normalized by the annual average of total assets. The horizontal axes show the quantiles. The solid lines represent the coefficient on the interaction term between the G-SIB dummy and the extrapolated RRI when this is assumed to be zero before 2010 . The broken lines represent the $90 \%$ confidence intervals. 
Figure 14: Results of Quantile Panel Regressions with Time Dummies for Positive Part of SRISK

(a) $\Delta \mathrm{CoVaR}$

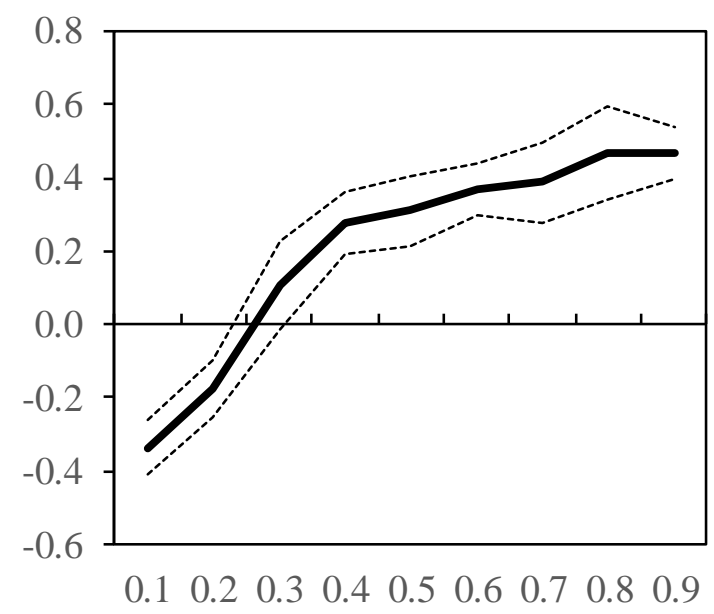

(b) SRISK

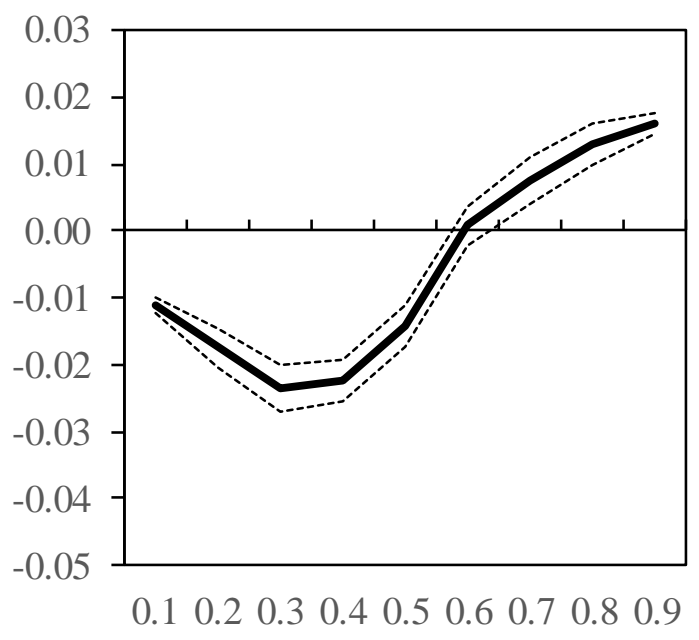

(c) SRISK minus all TLAC

(b) SRISK minus half of TLAC

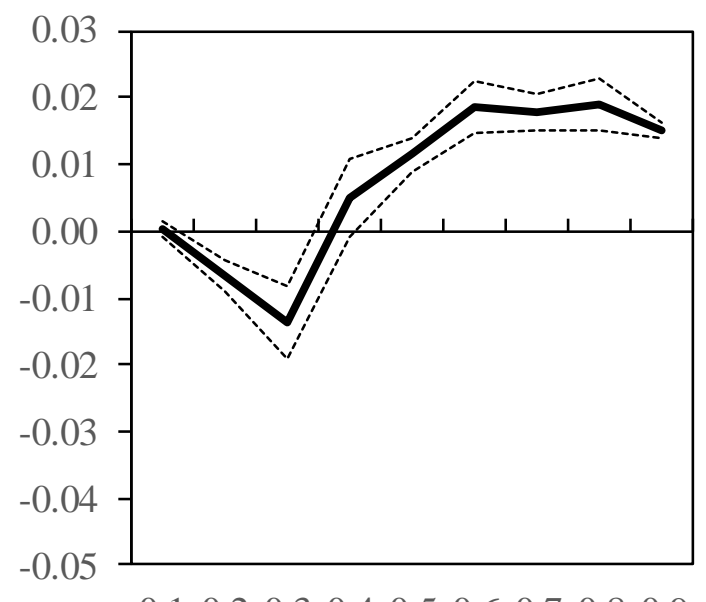

0.10 .20 .30 .40 .50 .60 .70 .80 .9

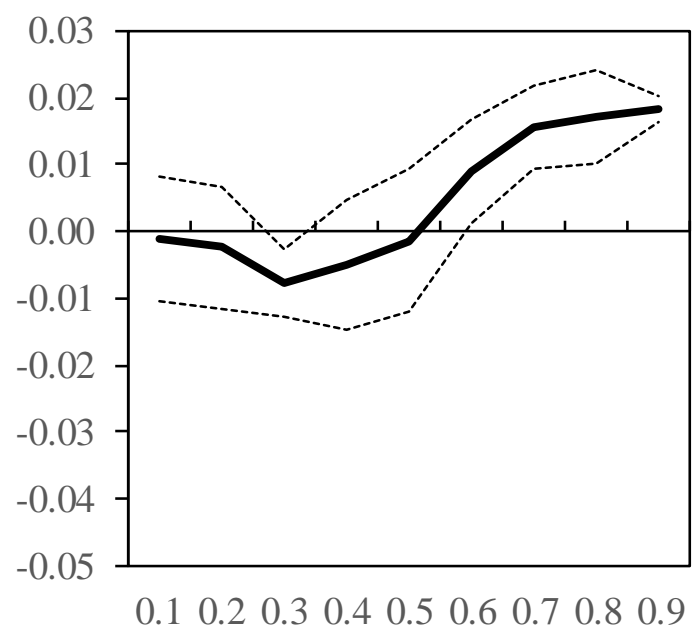

Note: Panels (a), (b), (c), and (d) show the estimation results of quantile panel regressions with time dummies for $\triangle$ CoVaR, SRISK, SRISK minus half of TLAC debt, and SRISK minus all TLAC debt, respectively. The latter three use the positive part normalized by the annual average of total assets. Panel (a) is exactly same as that in Figure 12 and shown here for comparison with the other panels. The horizontal axes show the quantiles. The solid lines represent the coefficient on the interaction term between the G-SIB dummy and the pre-crisis dummy. The broken lines represent the $90 \%$ confidence intervals. 